\title{
Animal Feed from Microalgae Grown on Biogas Digestate as Sustainable Alternative to Imported Soybean Meal
}

\author{
Mohamed Elshamy ${ }^{1,2} \cdot$ Christine Rösch $^{1}$ (i)
}

Received: 2 November 2021 / Accepted: 18 January 2022 / Published online: 4 February 2022

(c) The Author(s) 2022

\begin{abstract}
This work investigates microalgae's potential to reduce North-Western Europe environmental burden from excess nitrogen polluting groundwater and provide an environmental replacement for current animal feed. Algae uptake nutrients from nutrient-rich digestate from biogas plants and turn them into high-value feedstock, which can substitute soybean meal imported from overseas and avoid deforestation of rainforests. Life cycle assessments were conducted based on novel and original data from engineers in academia and industry, acquired through pilot-scale research facilities in the UK, France, and Belgium. The findings of this study highlight the environmental impacts of three different technologies with varying scales of production. Mixotrophic algal feed production shows higher productivities and fewer energy demands than the phototrophic systems. Still, the process is less favourable due to higher impacts on human health and ecosystems than imported soybean meal, whereas the impact on resources is more negligible. Sensitive analysis indicates that further technological development, increased productivities, and renewable energy use can improve the environmental competitiveness of algal feedstock. Since this process is a promising solution for making feedstock out of excess nutrients and having an alternative source for imported soybean meal with a comparable, efforts to realize these improvements and successfully upscaling algal feedstock production in combination with biogas plants are justified and can improve the environmental footprint of algal biomass production.
\end{abstract}

\section{Introduction}

Microalgae have been an all-rounder in the field of the bioeconomy for more than 50 years, in the sense of their capacity to produce high-value products including food, feed, cosmetics and medicine, and third-generation biofuels in fresh or seawater or to be used in wastewater and flue gas treatment [1-3]. Regulating growth conditions, microalgae can be grown to produce algal biomass, which is rich in lipids, proteins, carbohydrates, vitamins, mineral salts, or carotenoids $[1,3]$. Their great potential has kept the research vigorously ongoing, especially in the field of fuel and feed. In North-Western Europe (NWE), two environmental and socio-economic challenges could be addressed by linking

Christine Rösch

Christine.roesch@kit.edu

1 Institute for Technology Assessment and Systems Analysis (ITAS), Karlsruhe Institute of Technology (KIT), Karlstraße 11, 76133 Karlsruhe, Germany

2 Present Address: Institute of Microsystems Engineering IMTEK, Freiburg University, Freiburg, Germany the microalgae and the biogas technology: first, the eutrophication of groundwater and second, the dependency on soybean imports to supply protein for food and feed.

Anaerobic digestion (AD) in NWE has become a robust, reliable, and widely used decentral technology to produce biogas converted into renewable electricity and heat or upgraded to methane and fed into the gas grid to substitute natural gas. The primary feedstock for anaerobic digestions (AD) in biogas plants is manure, crops such as maize, and organic waste [4]. Besides energy, the main output of biogas plants is the nutrient-rich digestate (NRD), which is applied as agricultural fertilizers. Since transportability of the NRD is somewhat limited, the concentrated NRD application can evoke at local scale high loads of nitrogen application which can exceed the nutrient demand of the plants grown on the fields. This, in turn, can lead to high nitrate concentration in the groundwater. Especially in sensitive areas, this eutrophication process is considered a critical issue for groundwater quality and human health in NWE. Microalgae can tackle the eutrophication challenge because of their ability to uptake nutrients from waste streams. By this, the nutrient load from spreading nutrient-rich digestate from biogas plants can 
be reduced, and the eutrophication impacts in vulnerable groundwater areas can be reduced [5].

The second socio-economic and environmental challenge in NWE is the dependability on soybean meal (SM) imports to satisfy the demand for food and feed protein, especially in pig farming [6]. Soybean is one of the most important crops in the world to fulfil the need for feed, food, and biofuel $[7,8]$, and the global production area has been increased from 23.8 million hectares in 1961 to 120.5 million hectares in 2019 [9]. Due to climatic conditions, they are mainly imported from South America [10], a key region in the world market for soybean, with Brazil, Argentina, Paraguay, and Uruguay being major producers and exporters worldwide. Since soybeans are mainly destined for animal feeding, their production plays a fundamental role in the environmental sustainability of the growing world livestock activities [11], which are currently attributed to the most significant impacts of agriculture [12]. Soybean production has negative consequences for the environment, especially for preserving biodiversity. It requires long-distance overseas transportation and arable land, resulting in further rainforest deforestation in the SM exporting countries [10]. In addition to the environmental damage, SM imports are also considered risk factors for the independence and resilience of the NWE food system and sustainable food supply.

Cultivating microalgae in local technical systems can reduce Europe dependency on soybean imports and the associated environmental drawbacks. This is possible without intensifying land use competition at the same time since microalgae cultivation has very high efficiency and a low requirement for land, which does not need to be high-quality arable land. Besides, the production of an algal substitute for animal feed can facilitate the establishment of local value chains. Some microalgae species like Spirulina, Chlorella vulgaris, Scenedesmus, and Porphyridium sp. are evaluated to be suitable, even preferred as the protein source for some animals, mainly fish, poultry, and pigs [13]. Microalgae have a great potential to produce a protein with a significantly lower environmental impact. However, this requires further research and development and a changed framework regarding the energy system. Comparative life cycle analysis (LCA) shows that the resource footprint of the large-scale soy meal production is 102 lower than small-scale microalgae production in ponds in the Netherlands [10]. The algae's poor performance is mainly due to the energy-intensive microalgae cultivation. Taelman et al. (2015) pointed out that higher algae productivity and the use of renewable energy could significantly decrease the environmental impact of microalgae feed production [10].

This work aims to investigate the environmental impacts of the combination of microalgae cultivation with different technologies and biogas production to reduce the nitrogen loads from NRD and replace soybean imports by the production of protein-rich feed for pigs in particular piglets [5]. The focus of the research is the comparative implementation of life cycle assessments based on primary experimental data from three different microalgae pilot plants in the UK, France, and Belgium applying NRD from biogas plants fed with agricultural waste (e.g. manure) and carbon-rich biogenic waste (e.g. from the food industry) for the cultivation of microalgae.

\section{Methods and Materials}

\section{LCA Methodology}

The method applied was LCA as this is a standardized analysis tool for compilation and evaluation of the inputs, outputs, and potential environmental impacts of a product system throughout its life cycle. In other words, it covers the environmental impact of every stage of a product or a system, from the utilized raw materials and their extraction, the production processes of the products, the operational impact "use phase", and the end of life "disposal" [14].

This study follows the recommendations of the ISO 14040 and 14,044 frameworks regarding goal and scope definition, inventory analysis, life cycle impact assessment (LCIA), and interpretation, as shown in Fig. 1. The tool used to carry out the LCA is openLCA version 1.10, an open-source software with a broad range of compatible databases and assessment methods that help to quantify the impact of different processes on the environment. The unit processes are selected from ecoinvent 3.5 , which is used as the primary database. Ecoinvent provides real-life data in the form of "flows" that are interconnected with the environmental data of these flows [15].

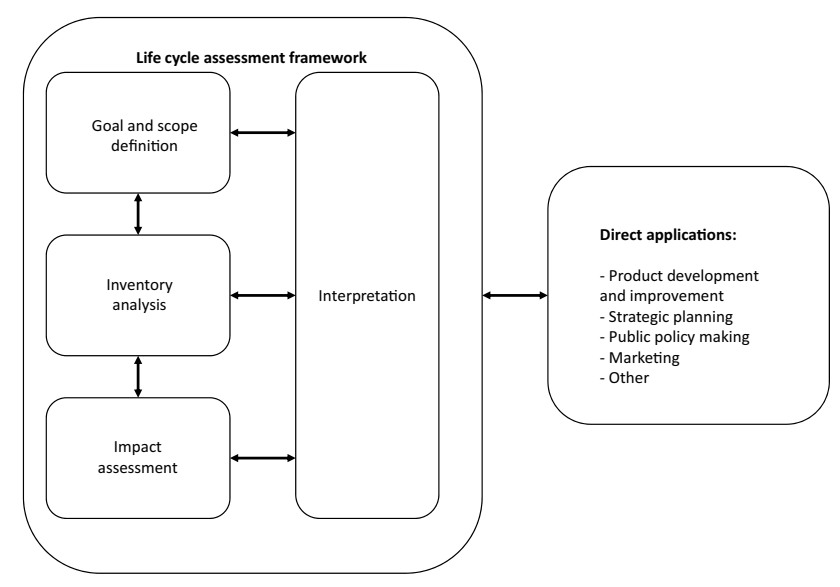

Fig. 1 Stages of an LCA [14] 


\section{Goal and Scope of the Study}

The overall aim of the Interreg NWE funded interdisciplinary research project "ALG-AD-Creating value from waste nutrients by integrating algal and anaerobic digestion technology" bringing together a group of scientists and engineers from 11 different partners from academics and industry in four countries across the NWE was to develop a circular economy solution to create wealth from waste by the integration of the algae technology into the NRD stream produced by anaerobic digestion plants by extraction and reduction of excess nitrate and making use of the scarce phosphorus. The goal of this study is to assess the life cycle of the ALG-AD technologies for their environmental impacts and to have valuable insights concerning the combination of biogas production and microalgae cultivation.

The three pilot plants are located in the NWE region, specifically, the UK (Langage-SU), Belgium (Innolab-UG), and France (CNRS-UBO). This region is characterized by wet and windy weather with intermediate temperature variations. The pilot plants are designed in combination with or as an extension of three different biogas plants where an $\mathrm{AD}$ is used to produce biogas from crops, agricultural, and food waste as feedstock. After dilution and treatment, the liquid fraction from the NRD produced by the $\mathrm{AD}$ is applied as a nutrient source to microalgae. The cultivated microalgae are harvested, partially dried, and post-treated as animal feed.
The LCA compares the combined algal AD technology with an existing animal feed production, considering that the algal-based feed product will substitute the traditional feed product. This work defines SM from Brazil as the reference product since it is commonly used as animal feed in the NWE region. Hence, overseas transportation and occupation of agricultural lands could be avoided by replacing SM with algae-based animal feed. Figure 2 shows the process outline of the ALG-AD.

\section{Functional Unit and System Boundaries}

The overall functional unit (reference product) of the ALGAD technology is described as " $1 \mathrm{~kg}$ dry mass of algaebased animal feed". This functional unit shall consider and credit potential by-products and alternative functions (such as excess energy of the AD process, produced fertilizer, avoided emissions from NRD storage and spread) resulting from the overall system.

The general approach of the LCA is gate-to-gate. It, therefore, does not include production, collection, and delivery of the biomass feedstock for anaerobic digestion and excludes the use of algae-based feed additive in livestock production (end product). The system boundaries of the LCA are shown in Fig. 3. The upstream processes include the production, pre-treatment of the digestate, and microalgae cultivation. The downstream processes include the harvest

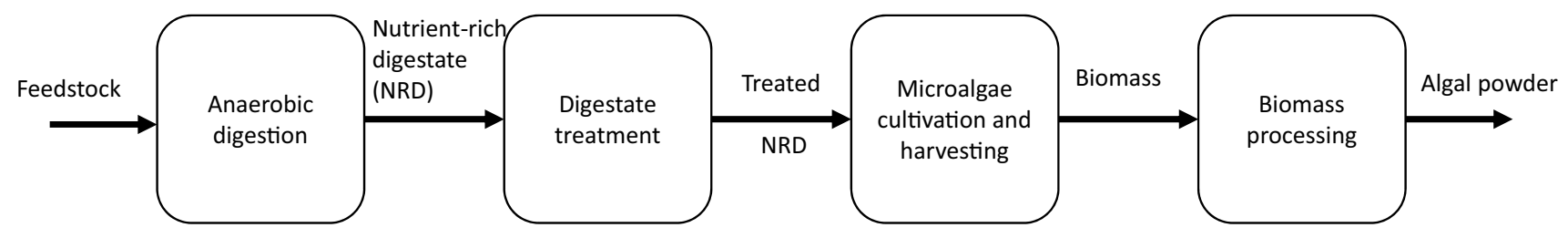

Fig. 2 LCA system boundaries of the combined algae and biogas process and single steps included in the LCA

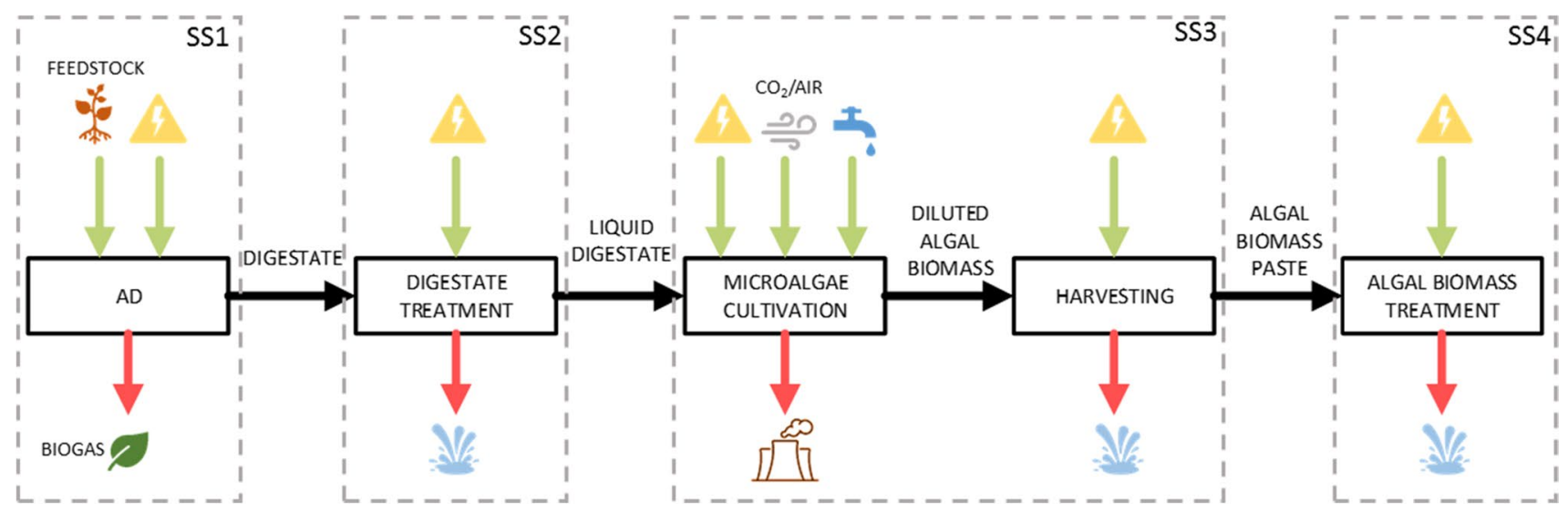

Fig. 3 Generic LCA model of combined algae and anaerobic digestion (ALG-AD) technology with four subsystems and their major inputs and outputs 
and post-treatment to process the algal biomass to the feed product. The overall ALG-AD technology system (Fig. 3) consists of four subsystems (SS):

- SS1: Anaerobic digestion (including the combined heat and power plant)

- SS2: Digestate processing (separation of solids, nutrient separation, and preparation, i.e. dilution with water)

- SS3: Microalgae cultivation (inoculation, cultivation, and harvest)

- SS4: Algae biomass processing (incubation and spray drying)

Within the system boundaries, the following inputs and outputs are considered:

- Material input and output flows and their production processes: biomass feedstock, freshwater, glucose feedstock, additional nutrients, chemicals for cleaning, ammonia emissions during biogas production, and NRD storage

- Energy inputs, outputs, and internal usage: for digestate processing, pumping the NRD fertilizer and carbon source supply to the algae culture as nutrient and for $\mathrm{pH}$ control, heating and cooling the photo-bioreactor (PBR), and harvesting and processing the algal biomass

- Construction and infrastructure: buildings, greenhouse, filters, storage tanks for NRD fertilizer, pipelines, pumps, microalgae cultivation reactors, centrifuge, and incubation tank

The temporal boundary reflects a 1-year baseline period of the technology. Therefore, all data (by considering lifespan and useful life of construction, appliances, or tools) is annualized accordingly.

\section{ALG-AD Pilot Plants and Case Studies Outline and Description}

This section describes three different ALG-AD pilot plants with combined algae and biogas technology and their specific settings and configurations: Langage-SU, CNRS-UBO, and Innolab-UG. The description is based exactly on how the real experiments were conducted without any improvement or literature-based protocols. More details about the subsystems are discussed in the "Life Cycle Inventory (LCI)" section.

\section{Langage-SU}

The company Langage is active along the entire value chain, from the herding of cows to the sale of the dairy product. They have designed a closed-loop system consisting of the Langage Dairy Farm with 250 cows, the Langage AD plant, and the dairy production unit. The company uses bio-fertilizer (digestate) from the AD plant to grow lush grass to feed its Jersey herd, which then produces the rich Jersey milk, which is turned into dairy products such as clotted cream and ice cream and yoghurt. Wastes from both the product outlets and the dairy products factory are brought back to the AD plant to produce electrical power, heat, and fertilizers required to run the Langage closed-loop system.

In this section, the base scenario of the ALG-AD pilot facility Langage-SU is described reflecting that of the actual pilot plant which is located within the AD plant Langage-SU in Plymouth and operated in association with Swansea University (SU), both located in the UK (Fig. 4). Being located within the $\mathrm{AD}$ plant complex, the digestate treatment, microalgae cultivation, and harvesting take place in a specially built greenhouse. The AD consists of three digesters fed with food waste and waste from dairy products. A combined heat and power plant (CHP) is affiliated to the plant, where the biogas is used to produce electricity and heat, for internal and external use. The digestate is treated on-site to separate the solid part from the liquid part. The solid part is then sun-dried and transported for use as a fertilizer, whereas the liquid part is further filtered and stored in a digestate storage tank to be used in the microalgae cultivation phase. Concerning the cultivation of microalgae, Chlorella vulgaris is the specie of choice. The culture is first cultivated under phototrophic conditions and then under mixotrophic conditions before the algal biomass is harvested. Through hydrolyzation, the biomass can be treated to increase the bioavailability of the ingredients, respectively, the protein content, and then dried to be eligible for use with the animal feed.

\section{CNRS-UBO}

This part entails the base scenario of the ALG-AD CNRSUBO's case study, where the processes to be mentioned reflect those of the actual pilot plant located in Brest (France) within the University of Western Brittany (UBO) and being investigated in close cooperation with the French National Centre for Scientific Research (CNRS), both located in France (Fig. 5). UBO is closely interlinked with the company Cooperl which is an agricultural and agri-food cooperative of the Grand-Ouest region of France. Over the years, it has become the French leader in pork with a very strong capacity for innovation and a perfect mastery of all the links in the chain from breeding, genetics, animal nutrition, building equipment, slaughtering and processing, and salting to a network of butcher's shops and delicatessens and even on-farm shops. Beyond that Cooperl operates a centre based on the circular economy which is dedicated to the recycling of effluents into organic fertilizers, energy (steam, biogas, and biofuels), and recycled water. 


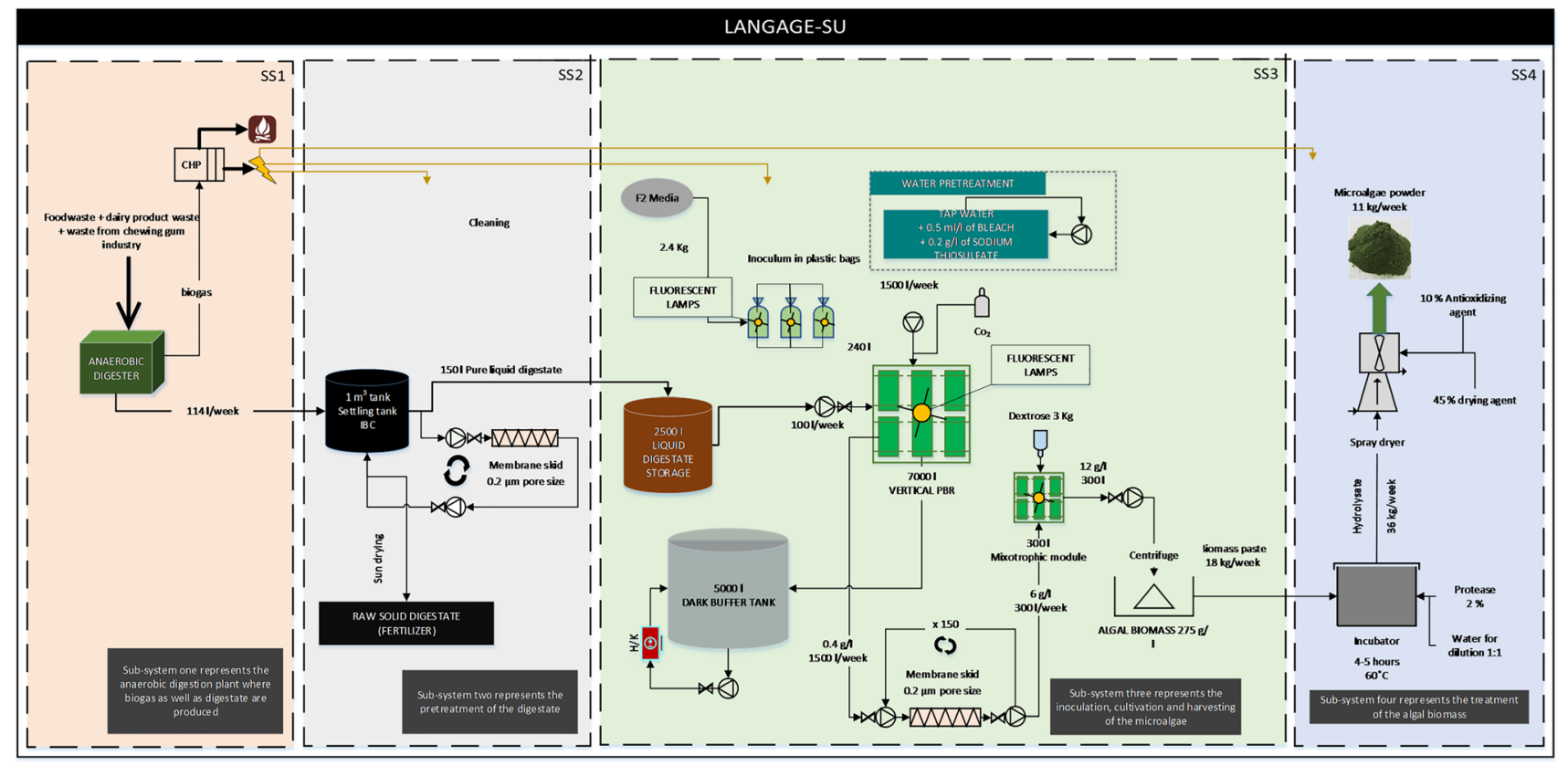

Fig. 4 LCA model with four subsystems of the ALG-AD pilot plant Langage-SU in Plymouth, UK

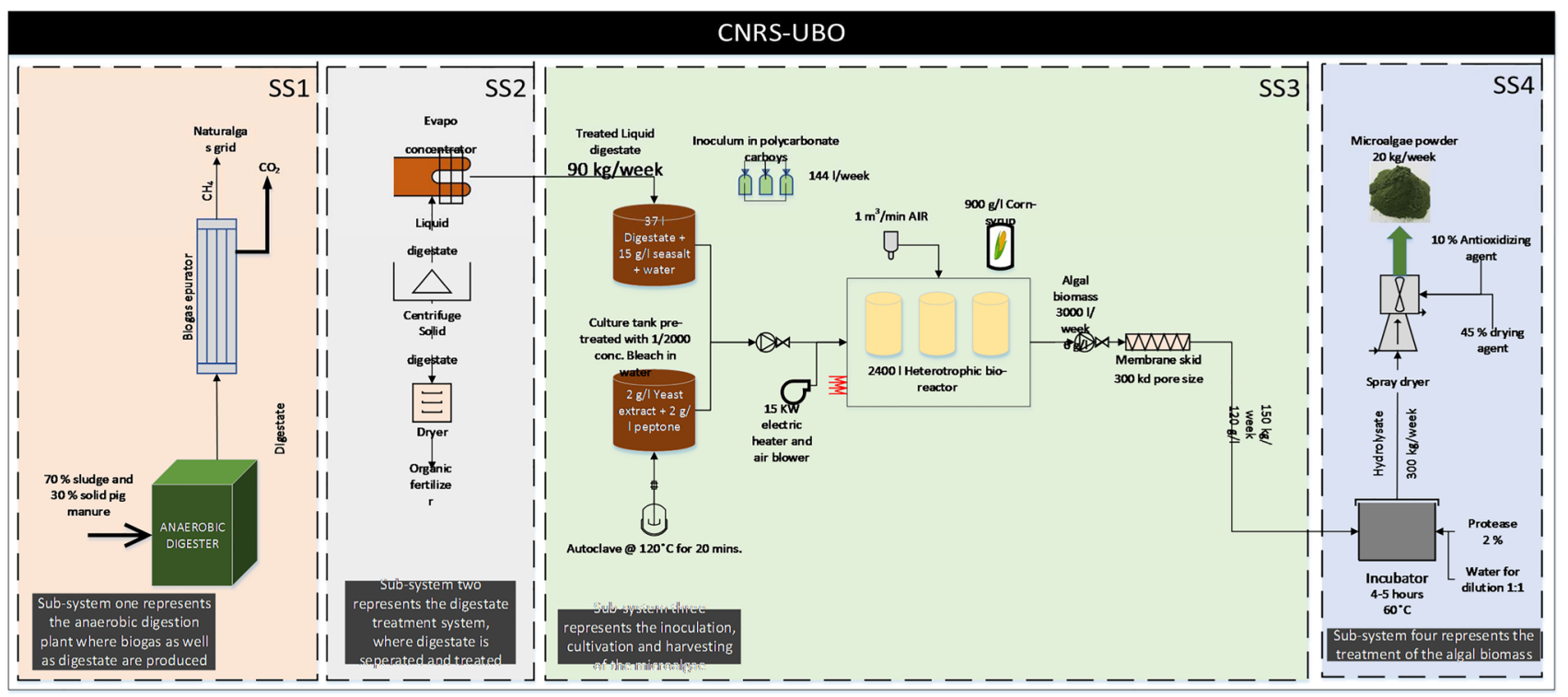

Fig. 5 LCA model with four subsystems of the ALG-AD pilot plant CNRS-UBO in Lamballe and Brest, France

The pilot plant for the cultivation of microalgae is located within the AD plant complex, however, in an uninsulated industrial building. The biomass feedstock is solid manure from local farms. Biogas is produced and sold to the national grid, while the energy required for running the plants is bought from the grid. The digestate is centrifuged, and the solid part is then dried and the liquid part delivered to the evapo-concentrator, to be filtered and purified. A heterotrophic-based reactor is used for microalgae cultivation. The species of microalgae used in this pilot is Aurantiochytrium $m$., which is a genus of eukaryotes. The algal biomass is harvested and treated to be used as animal feed. 


\section{Innolab-UG}

In this section, the base scenario of the Innolab-UG pilot facility at Innolab, located in Oostkamp, Belgium, and affiliated to the Ghent University, is described (Fig. 6). Innolab is a laboratory offering a wide range of services in connection with biogas production, purification of waste water, and analysis of biomass. They are a research and service laboratory with more than 10 years of experience in the entire analytical follow-up and technical guidance of biological purification and processing. The AD plant, which is located in Pittem, $20 \mathrm{~km}$ away from the pilot plant at Innolab, is using food waste as the main feedstock. A CHP converts the biogas into electricity and thermal energy for internal use and to be fed to the grid. The digestate is treated first at the AD plant through centrifugation. The solid part of the digestate is dried and used as a fertilizer, whereas part of the liquid part is taken to the microalgae pilot plant Innolab-UG and further filtered before added to the PBR. Microalgae species mixture of Chlorella and Scenedesmus is used. After inoculation in the lab, the culture grows in a multi-layer horizontal PBR, and the microalgae are continuously circulated in the PBR under the sun and flow through a dark tank triggering a mixotrophic phase.

\section{General Assumptions for the Three ALG-AD Pilot Plants}

The pilot facilities of the ALG-AD are assumed to operate in the same location without any renovation and under the same settings and policies for 11 months of the year. For 1 month, the plants are not in operation to allow for maintenance work and major cleaning. This period of inactivity is divided into 4 weeks, and it is assumed that this production stop will happen during 1 week every 3 months. However, regarding the ALG-AD pilot plant CNRS-UBO in France, the facility is assumed to be running for 12 months a year due to the simplicity of cleaning and maintaining the reactors.

Energy consumption during the inoculum preparation at the ALG-AD pilot plants Langage-SU and Innolab-UG was not considered, as it is done only at the beginning of the pilot plant operation and due to the negligible impact of this process in comparison to the whole system [16]. The embodied energy during the production and transport of equipment was not considered due to the complexity of acquiring such information. This complexity is based on the lack of reliable communication with the manufacturers and/or confidentiality. Considering a lifetime of only 1 year, constructions and equipment used within this pilot facility are assumed to have a maintenance-free 1-year operation. Since the pilot facility Langage-SU in Plymouth is located on-site of the AD plant, no transportation impact is included. The microalgae cultivation is assumed to be stable with continuous production throughout 1 year and with no contamination or crush of cultures. All the processes are done on-site with no transportation requirements to subcontractors. There was no monitoring of emissions within the pilot facilities, and hence, data for gaseous emissions were not included.

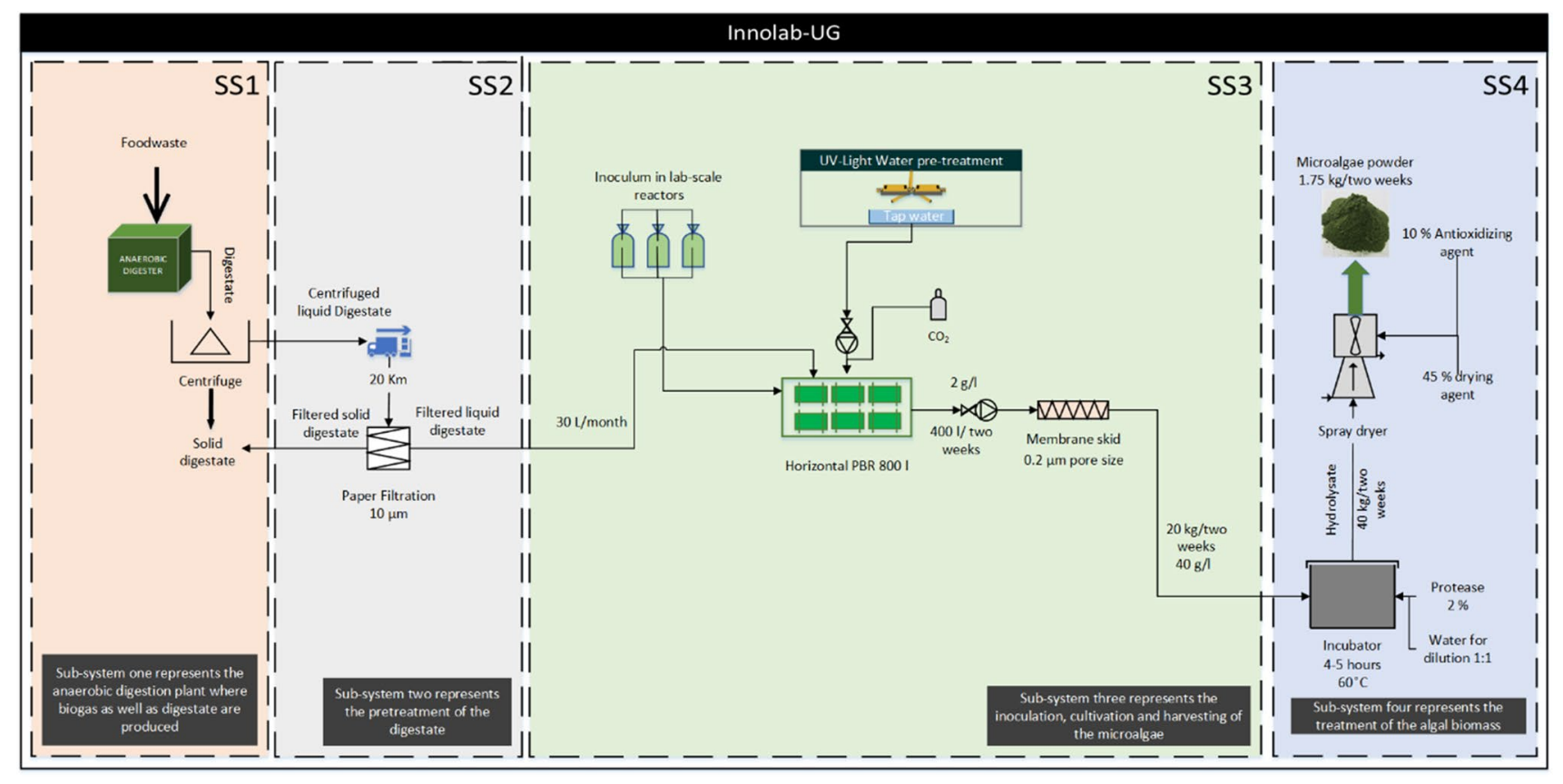

Fig. 6 LCA model with four subsystems of the ALG-AD pilot plant Innolab-UG in Pittem and Oostkamp, Belgium 


\section{Life Cycle Inventory (LCI)}

Data acquisition is a very challenging yet sensitive step in LCA. It depends on the reliability of the source, from a feasibility point of view and a veracity point of view. It also depends on the compatibility of these data with the database that is being used in the assessment, because in most cases, it is very hard to obtain and create LCA elements without having the background data at hand. Be it personal communication or literature review, there are challenges with the ease and willingness of providing the data in a profound manner and challenges with the accuracy, punctuality, and availability of the data, especially for new technologies and processes. In this study, primary data from the project partners working in the pilot facilities are used; however, some literature-based data was essential to create elements that were not provided or found on the database. Information about the equipment was gathered from the manufacturers' websites and/or by interviewing colleagues from the relevant technical departments. Background data was based on ecoinvent database v3.5 [17].

Table S1 shows the inputs and outputs of the three ALGAD pilot plant base scenarios presenting two different cultivation technologies, which are compared during this assessment. Inputs and outputs of the LCA model including equipment, materials, and consumables data are found in Table 1. The negative numbers for the nutrients nitrogen, potassium, and phosphates displayed in Table 1 are given to acknowledge and model the reduced environmental impacts by the avoided nutrient excess from the digestate, which is up taken by microalgae instead of being wasted as shown in the cultivation section of Table 1 . All equipment used at the microalgae facility is modelled according to available data, either from the partners, manufacture websites, or contacts in the industry. The details for the equipment mentioned as items in Table 1 will be found in Table S2 in the supplementary information.

\section{Anaerobic Digestion and Biogas Plant (Subsystem 1)}

In this section, details about the $\mathrm{AD}$ plant at each of the three ALG-AD pilot facilities are communicated. Since the AD plants at the three locations are not entirely part of the project, not enough data could have been provided by the operators for a detailed description of subsystem 1 . Therefore, for this study, readily available AD plants, as well as CHP units taken from the ecoinvent database v3.5, were scaled accordingly to conform to a more realistic and consistent estimate.

Langage-SU The Langage-SU AD plant comprises three mesophilic digesters each of $1,000 \mathrm{~m} 3$ in volume. The digester is fed with around 20, $000 \mathrm{t}$ /year of feedstock from food waste and dairy. The AD plant produces $80,000 \mathrm{t} / \mathrm{year}$ of digestate and 1.8E6 m3/year biogas. The total produced energy by the CHP unit is around $500 \mathrm{kWh} /$ year, from which the pilot facility is powered. However, the data used in this study is based on a readily available process on ecoinvent v3.5 [18] and is scaled up to the size of that of the AD plant in Langage. For the CHP, also a readily available process from ecoinvent is used, representing the one in Langage-SU.

CNRS-UBO The AD plant located in Lamballe, France, has a mesophilic digester volume of $15,000 \mathrm{~m} 3$ and is fed with wastewater from the slaughterhouse, pig manure, and recycled water. The plant produces around 156, $000 \mathrm{t}$ of raw digestate per year and $530 \mathrm{~m} 3 / \mathrm{h}$ of bio-methane, purified and fed to the gas grid. For this study, the data used for the AD plant is based on the readily available AD process, which was also used for Langage, however, employing a higher scaling factor. As Systemic does not have a CHP unit on site, subsystem 1 for CNRS-UBO comprises only the AD plant.

Innolab-UG The AD plant belonging to the ALG-AD system of Innolab-UG is not located at the PBR site but in Pittem. With a capacity of $180,000 \mathrm{t}$ of feedstock per year, the four digesters and a post-digester with a total volume of 20, $000 \mathrm{~m} 3$ are fed with organic bio-waste, manure, and other waste sources. Through the CHP unit, the plant can produce around 32,500 MWh and 29, $100 \mathrm{MWh}$ of heat and electricity per year, respectively. The readily available $\mathrm{AD}$ process [19] is scaled up to model the one in Pittem. Two readily available CHP processes are selected with the same load for the CHP unit.

\section{Digestate treatment (Subsystem 2)}

After disclosing the data used for the AD plant and the CHP unit, subsystem 2 (see Figs. 4, 5, 6) considers the treatment of the digestate before adding it to the cultivar. In addition to the on-site treatment of the digestate at the AD plant, where separation of the solid digestate is essential for fertilizing applications, the digestate is further treated at the pilot facility for sterilization and further separation of the concentrate. The technology used at each location and its details are described in the following subsections.

Langage-SU At Langage-SU, the digestate is treated at the microalgae facility through filter membranes. A $0.2-\mu \mathrm{m}$ mesh size filter membrane is used along with a dirty pump for $2 \mathrm{~h}$ for every $150 \mathrm{~L}$ digestate treated. The solid part is separated and dried and added to the solid fertilizer. The liquid portion is stored in a $1,000-\mathrm{L}$ intermediate bulk container (IBC) tank at the facility to be ready for use during the cultivation process. 
Table 1 Inputs and outputs of the LCA model of the three ALG-AD pilot plants

\begin{tabular}{|c|c|c|c|c|}
\hline & \multicolumn{3}{|c|}{ ALG-AD pilot plants } & \multirow[b]{2}{*}{ Unit } \\
\hline & Langage-SU & CNRS-UBO & Innolab-UG & \\
\hline Greenhouse & 140 & - & 52 & $\mathrm{~m} 2$ \\
\hline \multicolumn{5}{|c|}{ Subsystem 2: digestate treatment } \\
\hline \multicolumn{5}{|l|}{ Inputs } \\
\hline Untreated digestate & 5 & $1.56 \mathrm{E}+05$ & 1.6 & ton/yr \\
\hline Filter membrane & 1 & - & - & Items \\
\hline Electricity & 77 & 36,500 & - & $\mathrm{kWh} / \mathrm{yr}$ \\
\hline Mobile pump & 1 & - & - & items \\
\hline Polyethylene & 12.7 & - & - & $\mathrm{kg} / \mathrm{yr}$ \\
\hline Paper filter & - & - & 1 & Items \\
\hline Centrifuge & - & 1 & - & Items \\
\hline Polyacrylamide & - & $5.00 \mathrm{E}+04$ & - & $\operatorname{ton} / \mathrm{yr}$ \\
\hline \multicolumn{5}{|l|}{ Output } \\
\hline Treated digestate & 4 & $1.70 \mathrm{E}+05$ & 1.5 & $\operatorname{ton} / \mathrm{yr}$ \\
\hline \multicolumn{5}{|c|}{ Subsystem 3: microalgae cultivation and harvesting } \\
\hline \multicolumn{5}{|l|}{ Inoculation } \\
\hline \multicolumn{5}{|l|}{ Inputs } \\
\hline Glass tube & 0.01 & 2 & 0.01 & $\mathrm{~kg} / \mathrm{yr}$ \\
\hline Polyethylene & 0.0005 & 1 & 0.0005 & $\mathrm{~kg} / \mathrm{yr}$ \\
\hline $\mathrm{F} / 2$ media & 2.5 & - & - & $\mathrm{g} / \mathrm{yr}$ \\
\hline Glucose & - & 46 & - & $\mathrm{kg} / \mathrm{yr}$ \\
\hline Yeast & - & 0.2 & - & $\mathrm{kg} / \mathrm{yr}$ \\
\hline Sea salt & - & 34.5 & - & $\mathrm{kg} / \mathrm{yr}$ \\
\hline Water & 1 & 6.8 & 0.5 & $\mathrm{~m} 3$ \\
\hline Electricity & - & 2 & - & $\mathrm{MWh} / \mathrm{yr}$ \\
\hline \multicolumn{5}{|l|}{ Output } \\
\hline Inoculum & 1 & 6.9 & 0.5 & $\operatorname{ton} / \mathrm{yr}$ \\
\hline \multicolumn{5}{|l|}{ Photo-bioreactors } \\
\hline \multicolumn{5}{|l|}{ Inputs } \\
\hline Polyethylene & 500 & - & 9 & $\mathrm{~kg}$ \\
\hline Polymethyl methacrýlate & 505 & - & - & $\mathrm{kg}$ \\
\hline Polyvinylchloride & 590 & 40 & 40 & $\mathrm{~kg}$ \\
\hline Galvanized steel & 5.7 & - & 0.4 & $\operatorname{ton} / \mathrm{yr}$ \\
\hline Borosilicate glass & - & - & 133 & $\mathrm{~kg}$ \\
\hline Stainless steel & - & - & 20 & $\mathrm{~kg}$ \\
\hline Polyethylene terephthalate & - & 67 & - & $\mathrm{kg}$ \\
\hline \multicolumn{5}{|l|}{ Cultivation } \\
\hline \multicolumn{5}{|l|}{ Inputs } \\
\hline Electricity & 51 & 26.3 & 0.74 & $\mathrm{MWh} / \mathrm{yr}$ \\
\hline Treated digestate & 4 & 4.3 & 1.6 & $\operatorname{ton} / \mathrm{yr}$ \\
\hline Inoculum & 1 & 6.9 & 0.5 & ton/yr \\
\hline $\mathrm{CO} 2$ & 450 & - & 35 & $\mathrm{~kg} / \mathrm{yr}$ \\
\hline Glucose & 132 & 2,590 & - & $\mathrm{kg} / \mathrm{yr}$ \\
\hline Fluorescent lamp & 40 & - & - & Items \\
\hline Heat pump & 1 & - & - & Items \\
\hline Water & 66 & 144 & 10 & $\mathrm{~m} 3 / \mathrm{yr}$ \\
\hline Nitrogen & -147 & -100 & -35 & $\mathrm{~kg} / \mathrm{yr}$ \\
\hline Phosphates & -2.5 & -3 & -0.08 & $\mathrm{~kg} / \mathrm{yr}$ \\
\hline Potassium & -29 & -27 & -21 & $\mathrm{~kg} / \mathrm{yr}$ \\
\hline Pumps & 3 & 2 & 1 & items \\
\hline
\end{tabular}


Table 1 (continued)

\begin{tabular}{|c|c|c|c|c|}
\hline & \multicolumn{3}{|c|}{ ALG-AD pilot plants } & \multirow[b]{2}{*}{ Unit } \\
\hline & Langage-SU & CNRS-UBO & Innolab-UG & \\
\hline Yeast & - & 3.8 & - & $\mathrm{kg} / \mathrm{yr}$ \\
\hline Seawater & - & 1.44 & - & $\operatorname{ton} / \mathrm{yr}$ \\
\hline Blower & - & 1 & - & items \\
\hline \multicolumn{5}{|l|}{ Outputs } \\
\hline Cultivar & 11.26 & 144.5 & 8.8 & $\operatorname{ton} / \mathrm{yr}$ \\
\hline \multicolumn{5}{|l|}{ Harvesting } \\
\hline \multicolumn{5}{|l|}{ Inputs } \\
\hline Electricity & 0.96 & 9 & 0.12 & $\mathrm{MWh} / \mathrm{yr}$ \\
\hline Cultivar & 11.26 & 144.5 & 8.8 & $\operatorname{ton} / \mathrm{yr}$ \\
\hline Filter membrane & 1 & 1 & 1 & items \\
\hline Centrifuge & 1 & - & - & items \\
\hline Pumps & 2 & 1 & 2 & items \\
\hline \multicolumn{5}{|l|}{ Output } \\
\hline Biomass paste & 0.82 & 7.2 & 0.44 & ton/yr \\
\hline Wastewater & 11 & 130 & 9 & $\mathrm{~m} 3 / \mathrm{yr}$ \\
\hline \multicolumn{5}{|l|}{ Cleaning } \\
\hline \multicolumn{5}{|l|}{ Inputs } \\
\hline Water & 348 & 713 & 84 & $\mathrm{~m} 3 / \mathrm{yr}$ \\
\hline Bleach & 150 & - & - & $\mathrm{kg} / \mathrm{yr}$ \\
\hline Sodium hydroxide & - & 240 & - & $\mathrm{kg} / \mathrm{yr}$ \\
\hline Sulphuric acid & - & 176 & - & $\mathrm{kg} / \mathrm{yr}$ \\
\hline Sodium metasilicate & 54 & - & - & $\mathrm{kg} / \mathrm{yr}$ \\
\hline \multicolumn{5}{|l|}{ Output } \\
\hline Wastewater & 346 & 670 & 84 & $\mathrm{~m} 3 / \mathrm{yr}$ \\
\hline \multicolumn{5}{|c|}{ Subsystem 4: algal biomass treatment } \\
\hline \multicolumn{5}{|l|}{ Incubation } \\
\hline \multicolumn{5}{|l|}{ Inputs } \\
\hline Electricity & 1.2 & 2.4 & 0.6 & $\mathrm{MWh} / \mathrm{yr}$ \\
\hline Biomass paste & 0.82 & 7.2 & 0.44 & $\operatorname{ton} / \mathrm{yr}$ \\
\hline Enzyme & 16.32 & 144.6 & 8.8 & $\mathrm{~kg} / \mathrm{yr}$ \\
\hline Polyethylene & 12.7 & 12.7 & 12.7 & $\mathrm{~kg} / \mathrm{yr}$ \\
\hline Incubator & 1 & 1 & 1 & items \\
\hline Water & 0.82 & 7.23 & 0.44 & $\mathrm{~m} 3 / \mathrm{yr}$ \\
\hline \multicolumn{5}{|l|}{ Output } \\
\hline Hydrolysate & 1.63 & 14.6 & 0.89 & $\operatorname{ton} / \mathrm{yr}$ \\
\hline \multicolumn{5}{|l|}{ Spray drying } \\
\hline \multicolumn{5}{|l|}{ Inputs } \\
\hline Electricity & 1.27 & 2.5 & 0.63 & $\mathrm{MWh} / \mathrm{yr}$ \\
\hline Hydrolysate & 1.63 & 14.6 & 0.89 & ton/yr \\
\hline Antioxidant & 44 & 87 & 3.4 & $\mathrm{~kg} / \mathrm{yr}$ \\
\hline Drying agent & 220 & 433 & 17.6 & $\mathrm{~kg} / \mathrm{yr}$ \\
\hline Spray dryer & 1 & 1 & 1 & items \\
\hline \multicolumn{5}{|l|}{ Output } \\
\hline Dried powder & 0.48 & 0.95 & 0.039 & ton/yr \\
\hline Wastewater & 1.15 & 13.6 & 0.85 & $\mathrm{~m} 3 / \mathrm{yr}$ \\
\hline
\end{tabular}

CNRS-UBO At Lamballe, France, the digestate is treated in two stages, the first is through a decanting centrifuge with the addition of polymer, and the second is through an evapo-concentrator. The treated digestate is then stored in a 1, 000-L IBC tank. 
Innolab-UG After treating the digestate at the AD plant in Pittem, some $80 \mathrm{~L}$ per week are transported to the microalgae facility in Oostkamp. The digestate is further filtered using the paper filtration technique to eliminate more solid chunks.

\section{Microalgae Inoculation, Cultivation, and Harvesting (Subsystem 3)}

This is considered to be the main subsystem of the ALGAD technology. It includes inoculation, cultivation of the algal species, and harvesting the algal biomass. For the three facilities, the inoculation process differs mainly in the algal species inoculated and the frequency of inoculation. There are many differences between the facilities for the cultivation, as will be discussed in the following subsections. This is also true for the different harvesting processes and frequencies.

Langage-SU The inoculation process starts in three lab-scale glass flasks of $1 \mathrm{~L}$ each and then moved to carboy bottles of $5 \mathrm{~L}$ each before they are added to three $80-\mathrm{L}$ polyethylene bags filled with water for final inoculation. The nutrients used during inoculation are in the form of $\mathrm{F} / 2$ media. After treatment, the growth medium is moved to the 7,000-L vertical tubular PBR (V-PBR) and diluted with fresh tap water. The tap water is chemically treated with bleach and sodium thiosulphate and is set in continuous motion using pumps to prevent bacterial contamination. The cylinders of the V-PBR are made of polymethyl methacrylate sheets (PMME), whereas the pipework and valves are made of polyvinylchloride (PVC). Stainless steel frames are used to support the PBR structure.

During cultivation, filtered digestate from subsystem 2 is added at an average of $90 \mathrm{~L} / \mathrm{batch}$. Liquid CO2 $(31 \mathrm{~L} / \mathrm{h})$, which comes in pressurized bottle packs, is continuously added to adjust the $\mathrm{pH}$ of the culture. A heat pump and a lighting system consisting of fluorescent lamps with an annual energy consumption of $34 \mathrm{MWh}$ and $1.8 \mathrm{MWh}$ are employed. For the circulation of the culture, a pump is used with an annual energy demand of $2 \mathrm{MWh}$. After 5 days of cultivation, around $15 \%$ of the cultivar is filtered in a $0.2-\mu \mathrm{m}$ mesh size filter membrane to concentrate the culture preparing for the mixotrophic phase. The mixotrophic bioreactor (MBR) is a downsized version of the PBR, where only around $250 \mathrm{~L}$ of the cultivar can be grown before centrifugation. The algal biomass production increases from a concentration of $0.4 \mathrm{~g} / \mathrm{L}$ in the PBR to $6 \mathrm{~g} / \mathrm{L}$ after membrane filtration and finally to $12 \mathrm{~g} / \mathrm{L}$ after 48-h growth period in the MBR. The mixotrophic phase requires an additional carbon input provided in the form of $3 \mathrm{~kg}$ dextrose per batch of $250 \mathrm{~L}$. A suspended centrifuge runs for $6 \mathrm{~h}$ every batch for the harvesting process, yielding $270 \mathrm{~g} / \mathrm{L}$ algal biomass paste.
CNRS-UBO This ALG-AD pilot CNRS-UBO differs from the other two ALG-AD facilities as here no prokaryotic microalgae but a unicellular eukaryotic heterotrophic fungus-like clade of Stramenopiles is applied. [20] Since they are considered as an increasingly important source of polyunsaturated fatty acids (PUFAs) for biotechnological industries, these organisms are subsequently referred to in some literature and marketing sources as being derived from "algae", despite their non-photosynthetic source organism. [21] The species Aurantiochytrium m. applied in CNRS-UBO belongs to the family of Thraustochytrids, which are associated with two main features responsible for the increasing interest in this family of microorganisms. They display high growth performance, reaching very high cell concentrations in a few days, and exhibit the striking ability to produce and accumulate docosahexaenoic acid (DHA). [19] In contrast with most microorganisms that produce saturated fatty acids as energy storage lipids, Thraustochytrids synthesize long chain-polyunsaturated fatty acids (LC-PUFAs), like DHA, as energy storage.

Aurantiochytrium $\mathrm{m}$. is cultivated under heterotrophic conditions in batch system production. This entails that the inoculation is freshly prepared for every batch. The inoculum is prepared in $1-\mathrm{mL}$ cryovials stored at $-80{ }^{\circ} \mathrm{C}$ then left for 6 days with the addition of $20 \mathrm{~g}$ glucose, $2 \mathrm{~g}$ yeast, $2 \mathrm{~g}$ peptone, and $15 \mathrm{~g}$ sea salt for every litre. The inoculum is then moved into 24-L carboy bottles filled with water. The bioreactor used at CNRS-UBO comprises three PET columns of $800 \mathrm{~L}$ total volume and $500 \mathrm{~L}$ active volume each. As the cultivation type is heterotrophic, this eliminates the application of lighting systems and carbon dioxide. However, to ensure optimal growth conditions, the aforementioned additives are added with the following quantities: $2.5 \mathrm{t} /$ year of $900 \mathrm{~g} / \mathrm{L}$ corn syrup as a source of glucose, tap water, and sea salt for digestate dilution and a mixture of yeast and peptides of around $4 \mathrm{~kg} /$ year each, diluted in tap water. Three IBC tanks of $1 \mathrm{~m} 3$ each are used to store those three additives. Circulation pumps are used at the beginning of each batch during the addition and starting of the culture, whereas an air-blower running at one-fourth of its power rating is operating continuously. The reactors are cleaned after every batch with water. The cultivar is harvested twice a week through a tangential flow filtration system that concentrates the diluted algal biomass to an average of $90 \mathrm{~g} / \mathrm{L}$ biomass paste to be further processed in subsystem 4 .

Innolab-UG At Innolab-UG, the inoculation is like that at Langage-SU, done only at the beginning of the cultivation period. Lab-scale inoculum preparation follows almost similar procedures like the one at Langage-SU with the only difference regarding the source of nutrients, whereas at Innolab-UG treated digestate in place of $\mathrm{F} / 2$ media is applied. A horizontal tubular PBR (H-PBR) with a volume of $800 \mathrm{~L}$ is used for the cultivation process. The lifetime of the H-PBR at Innolab-UG 
is estimated at around 10 years as it is made of glass, whereas that made of plastic would attain scratches from scrubbing and cleaning that would impact the light penetration through the tube walls, hence estimated to have around only 5 years lifetime. After filling the H-PBR with the inoculum and adding UV-treated tap water, the cultivation process runs for almost 3 weeks before being harvested. During this period, liquid carbon dioxide $(12 \mathrm{~L} / \mathrm{h})$ is supplied through pressurized bottles to adjust the $\mathrm{pH}$ of the cultivar. The cultivar grows on sunlight during the daytime; however, few fluorescent lamps are utilized to keep the culture from crashing during dark hours. The treated digestate is supplied at a rate of $30 \mathrm{~L} / \mathrm{month}$. After reaching a biomass concentration of around $2.7 \mathrm{~g} / \mathrm{L}$, about $500 \mathrm{~L}$ of the cultivar are filtered in a $0.2-\mu \mathrm{m}$ mesh size filter membrane reaching a concentration of $150 \mathrm{~g} / \mathrm{L}$.

\section{Biomass Treatment (Subsystem 4)}

Subsystem 4 covers the post-treatment of the algal biomass. The hydrogenation of the harvested algal biomass is carried out once for all three facilities simultaneously. Therefore, the data used for the LCA model is identical for all ALG-AD pilot facilities. However, each facility would be modelled to have the hydrolyzation equipment onsite. These are incubation tank with temperature and $\mathrm{pH}$ control, settling tank, and spray dryer. During the hydrogenation process, water for dilution is added depending on the amount of the harvested biomass with a 1:1 ratio and protease as the enzyme for hydrolyzation. Then, the hydrolysate is heated to $90{ }^{\circ} \mathrm{C}$ to stop the enzyme activity. After hydrolyzation, the hydrolysate is left to settle in an IBC tank as a conditioning step before going through the spray dryer. Modified starch is added to the biomass being dried as a protective agent to the algal biomass and ascorbyl palmitate, which acts as an antioxidant.

\section{Soybean Meal Production (Reference Scenario)}

Data used to model the soybean meal (SM) scenario is based on "Life cycle inventories of bioenergy". [22] which considers materials energy consumption, Land transformation and emissions. In contrast, data for overseas transportation is acquired from [23] the Central West (CW) scenario in Brazil, where more deforestation and transport take place.

\section{Life Cycle Impact Assessment (LCIA)}

One of the limitations of environmental impact assessment (LCIA) is that it can never account for all impacts, especially not in one analysis. However, a significant number of methods provide a reliable and, in most cases, good overview of the product's impact on the environment. ReCiPe 2016 midpoint $(\mathrm{H})$ is the chosen assessment methodology in this study. The authors of this method chose human health, ecosystem, and resource scarcity as the focus areas. For the NWE region, some of the most relevant and essential impact categories are addressed through this method: global warming potential (GWP), eutrophication, eco-toxicity, water depletion, and land use.

\section{Mass Balance}

The mass balances for the three ALG-AD pilot facilities are shown in figures $\mathrm{S} 1, \mathrm{~S} 2$, and $\mathrm{S} 3$ in the supplementary information. The mass balances depict the amounts of inputs and outputs to the main processes of the systems. A unit reference of 1 week was chosen as the average harvesting frequency between the three facilities. The difference between the diagrams in mass and volume units of the harvested biomass is due to the different measurements conducted by the technical partners and was left to avoid inaccurate calculations. The facility CNRS-UBO does not have an integrated CHP plant, so it was not included in the Figure. In subsystem 2, the mass balance shows the amounts of raw digestate being treated either at the biogas plant or on-site at the pilot facility. Most digestate are depicted as an out of boundary value with a dashed line.

\section{Results and Discussion}

\section{Base Scenario (LCA)}

In this study, the environmental impacts of three ALG-AD pilot facilities in different locations in the NWE region were analysed. The study comprises the LCA of microalgae cultivation while utilizing the NRD digestate from AD plants. The digestate composition and the efficiency of nutrient removal by the microalgae are shown in Table 2 . Moreover, the study incorporates the end product of the ALG-AD technology, which is $1 \mathrm{~kg}$ of animal feed. A

Table 2 Digestate composition of the three regions and the efficiency of nutrient removal through microalgae cultivation

\begin{tabular}{lllll}
\hline Element & $\begin{array}{l}\text { Langage- } \\
\text { SU } \\
(\mathrm{mg} / \mathrm{L})\end{array}$ & $\begin{array}{l}\text { CNRS- } \\
\text { UBO } \\
(\mathrm{mg} / \mathrm{L})\end{array}$ & $\begin{array}{l}\text { Innolab- } \\
\text { UG } \\
(\mathrm{mg} / \mathrm{L})\end{array}$ & $\begin{array}{l}\text { Assumed efficiency } \\
\text { of nutrient removal } \\
(\%)^{*}\end{array}$ \\
\hline Nitrogen & 4,474 & 2,480 & 2,370 & 92.5 \\
Phosphorus & 135 & 138 & 9.6 & 51.9 \\
Potassium & 1,360 & 1,054 & 2,130 & 62.9 \\
\hline
\end{tabular}

*Data from Scherer, Marisa Daniele, et al. 2017 [24] 
sensitivity analysis is also carried out to demonstrate and endorse possible technological improvements. Table 3 displays the different values of environmental impact categories based on the ReCiPe 2016 Midpoint (H) for the three base scenarios in the UK, France, and Belgium and the soybean meal imported from Brazil (reference scenario).

Following the endpoint area of protection approach, where the impact indicators are referred to three fundamental categories (human health, ecosystems, and resources through damage pathways) [25], the values in Table 4 could be collated and plotted as shown in Fig. 7a. The vertical axis is the relative impact of each of the three ALG-AD facilities on the three areas of protection (AoP). The Innolab-UG facility has the highest impact in each of the three AoP: human health, ecosystems, and resources. This is due to the relatively low biomass powder production of only $38.5 \mathrm{~kg}$ annually and the energy source coming from the electricity grid of Belgium. Although the Langage-SU facility has a more complex system comprising two-step cultivation and extra filtration cycle with relatively larger capacities and high-energy consumption from continuous heating and illumination, its contribution to all AoP is minimal compared to the other two facilities. This is mainly due to the internal usage of energy from the $\mathrm{AD}$ plant and the relatively high biomass powder production of $484 \mathrm{~kg}$ annually.

Figure $7 \mathrm{a}$ also presents the impact of SM import from Brazil to Europe. It is evident that the difference in environmental impacts compared to all three ALG-AD pilot plants is immense in the category of resources. However, an established industry like soybean production would generally have the edge over all other immature technologies, not to mention the difference in
Table 4 Present electricity mix of each country where the three ALGAD pilot facilities are located (2019)

\begin{tabular}{lccc}
\hline \multirow{2}{*}{$\begin{array}{l}\text { Data from 2019 (data and } \\
\text { statistics-IEA) }\end{array}$} & \multicolumn{3}{c}{ Electricity production mix (\%) } \\
\cline { 2 - 4 } & UK & France & Belgium \\
\hline Natural gas & 40.92 & 6.69 & 27.52 \\
Hard coal & 2.38 & 1.13 & 2.71 \\
Oil and other fossil fuels & 0.32 & 1.25 & 0.5 \\
Hydro power & 2.38 & 10.89 & 1.26 \\
Wind power & 19.81 & 6.07 & 10.21 \\
Solar power & 3.92 & 1.99 & 4.22 \\
Nuclear power & 17.36 & 69.90 & 46.55 \\
Bioenergy & 12.91 & 1.96 & 7.03 \\
Tide energy & 0.004 & 0.08 & - \\
Geothermal energy & - & 0.02 & - \\
\hline
\end{tabular}

scale. What is abundant through assessing the three systems is that the potential of the ALG-AD pilot facilities to produce at least twice their current capacity is easily attainable with only a slight increase in energy and material consumption. This would narrow the gap between the two industries even at the pilot scale. Langage-SU is already close to having the same footprint as SM even though only $300 \mathrm{~L}$ is harvested weekly from the mixotrophic reactor. As per S.E. Taelman et al., in the upscaling scenario, a decrease by a factor of 23 could be achieved in the consumption of natural resources [26]. That goes back to nutrients and other consumables recycling, like water and flue gas recovery, PBR design optimization, and more energy-efficient equipment.

Table 3 Impact results of the base scenarios of the ALG-AD pilot facilities and the reference scenario SM of $1 \mathrm{~kg}$ FU

\begin{tabular}{|c|c|c|c|c|c|}
\hline Impact category & Unit & Langage-SU & CNRS-UBO & Innolab-UG & SM \\
\hline Freshwater ecotoxicity (FET) & $\mathrm{kg} \mathrm{1,4-DCB}$ & 0.32382 & 0.58425 & 1.26337 & 0.02855 \\
\hline Freshwater eutrophication (FE) & $\mathrm{kg} \mathrm{P}$ eq & 0.00297 & 0.00667 & 0.01287 & 0.00056 \\
\hline Human carcinogenic toxicity (HT) & kg 1, 4-DCB & 0.78197 & 0.93444 & 2.98562 & 0.0577 \\
\hline Marine ecotoxicity (MET) & $\mathrm{kg} \mathrm{1,4-DCB}$ & 0.47109 & 0.84049 & 1.82017 & 0.04421 \\
\hline Ionizing radiation (IR) & kBq Co-60 eq & 0.66336 & 82.47724 & 69.34049 & 0.02635 \\
\hline Stratospheric ozone depletion (SOD) & $\mathrm{kg} \mathrm{CFC} 11 \mathrm{eq}$ & $8.9645 \mathrm{E}-06$ & $5.40 \mathrm{E}-05$ & $7.22 \mathrm{E}-05$ & $6.26 \mathrm{E}-06$ \\
\hline Ozone formation, terrestrial ecosystems (OF-TET) & kg NOx eq & 0.01608 & 0.05068 & 0.09577 & 0.00981 \\
\hline Terrestrial ecotoxicity (TET) & $\mathrm{kg} \mathrm{1,4-DCB}$ & 57.68807 & 79.6957 & 180.26584 & 2.70577 \\
\hline Mineral resource scarcity (MRS) & $\mathrm{kg} \mathrm{Cu} \mathrm{eq}$ & 0.06621 & 0.13714 & 0.39741 & 0.00689 \\
\hline Fine particulate matter formation (FPM) & $\mathrm{kg}$ PM2.5 eq & 0.0138 & 0.04745 & 0.13067 & 0.00932 \\
\hline Human non-carcinogenic toxicity (HNT) & $\mathrm{kg} \mathrm{1,4-DCB}$ & 11.02283 & 19.51126 & 33.29799 & 0.84371 \\
\hline Ozone formation, Human health (OF-HH) & kg NOx eq & 0.01525 & 0.0496 & 0.09238 & 0.00899 \\
\hline Terrestrial acidification (TA) & $\mathrm{kg} \mathrm{SO} 2 \mathrm{eq}$ & 0.03625 & 0.20585 & 0.68174 & 0.00873 \\
\hline Water consumption (WC) & $\mathrm{m} 3$ & 1.17977 & 1.80172 & 3.69232 & 0.00532 \\
\hline Marine eutrophication (ME) & $\mathrm{kg} \mathrm{N} \mathrm{eq}$ & 0.00227 & 0.0156 & 0.02194 & 0.00248 \\
\hline Land use (LU) & $\mathrm{m} 2 \mathrm{a}$ crop eq & 0.02525 & 0.09626 & 0.15355 & 6.60511 \\
\hline Global warming (GW) & $\mathrm{kg} \mathrm{CO} 2 \mathrm{eq}$ & 7.61395 & 24.61413 & 66.87257 & 1.46029 \\
\hline Fossil resource scarcity (FRS) & $\mathrm{kg}$ oil eq & 2.45168 & 8.37444 & 24.83046 & 0.27643 \\
\hline
\end{tabular}


a)

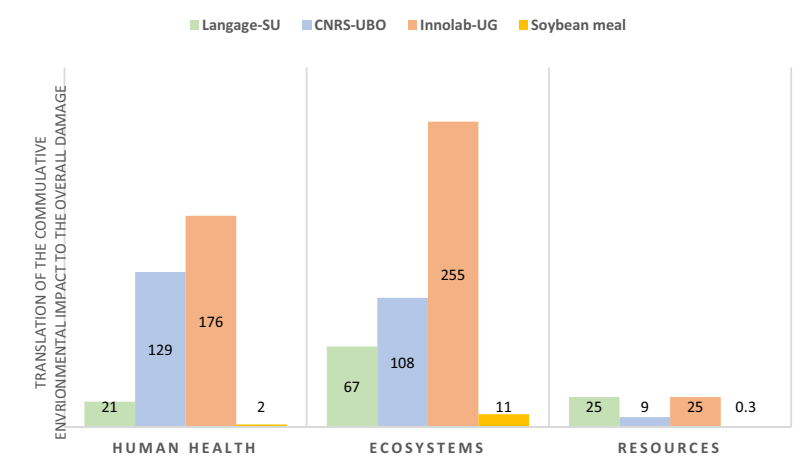

c)

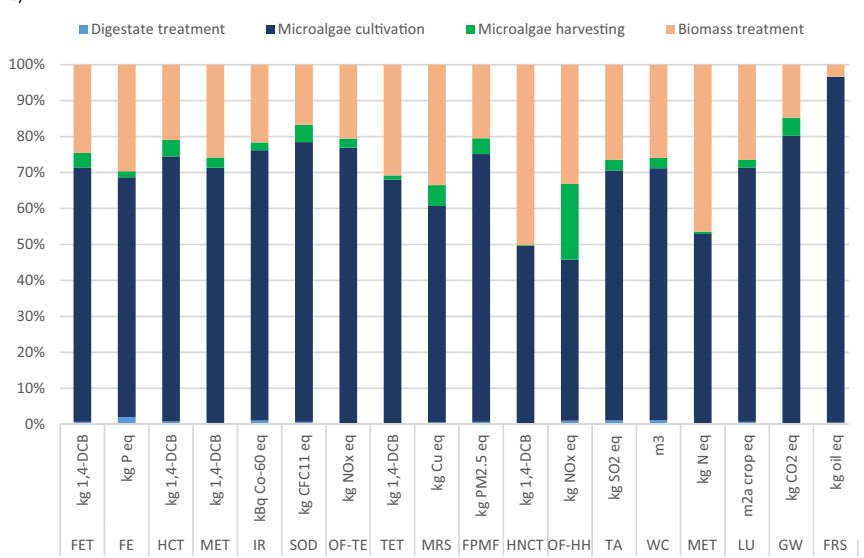

Fig. 7 a Overall contribution of the three ALG-AD pilot plants to the three main indicators of environmental impact, human health, ecosystems, and resources. $b$ Main process impact assessment of the

The other sub-figures of Fig. 7 depict the impact of the main processes of each facility following the usual Midpoint approach. Figure 7b assesses the Innolab-UG facility's base scenario and displays a remarkable result that contradicts many literature findings $[16,27,28]$ and the other two facilities, claiming that the microalgae cultivation process, and especially in tubular PBRs, is usually responsible for more than $80 \%$ of the total impact, since the productivity was averaged over 1 year with only a few weeks of poorly functioning cultivation, the facility engineers applied neither heating nor artificial lights at the reactor. This results in a significant decrease in consumables and equipment for the cultivation process. The biomass treatment is manifested in the case of Innolab-UG, due to the employment of the same posttreatment equipment as the ones in the other two facilities, however, with a significantly lower production rate.

In the case of Innolab-UG and CNRS-UBO, the digestate treatment process is prominent. This goes back to the intensive polymer use as a flocculant during the decanting centrifuge process, as shown in Fig. $8 \mathrm{~b}$ and c. The cultivation process at the CNRS-UBO facility is dominant compared
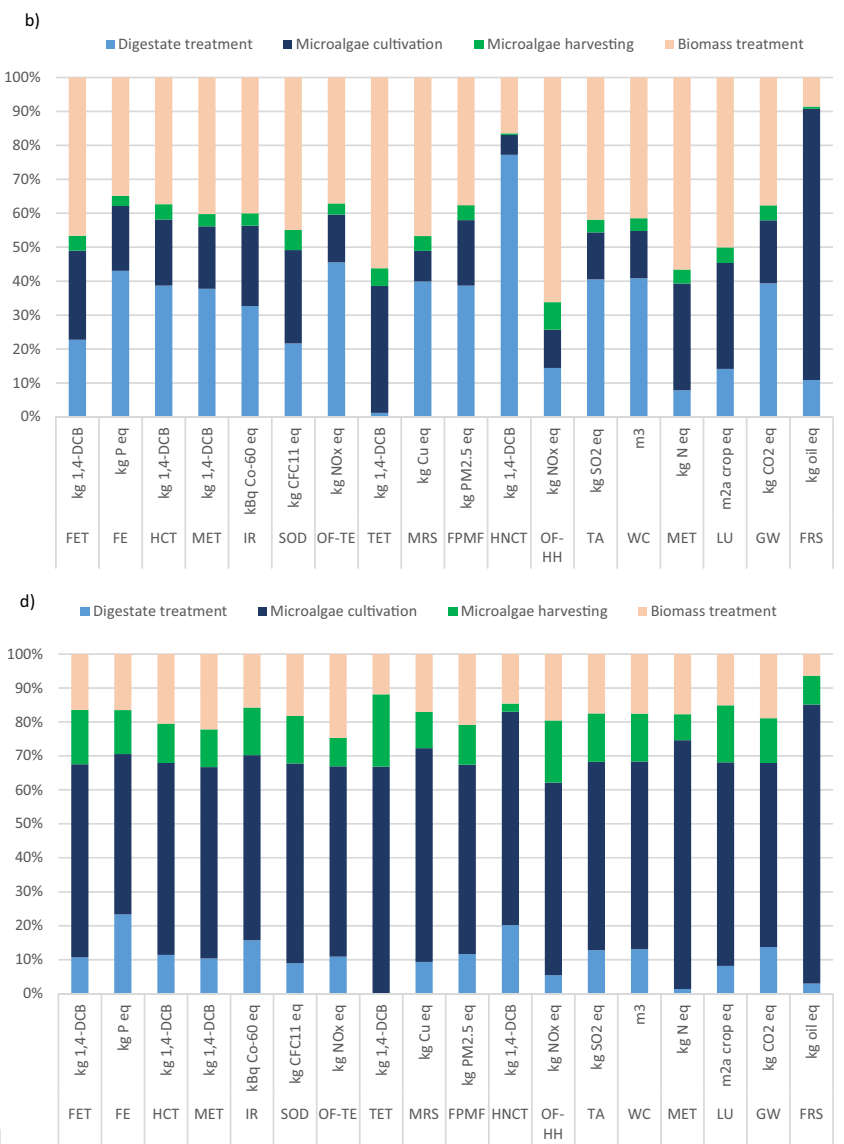

Innolab-UG facility. c Main process impact assessment of the Langage-SU facility. d Main process impact assessment of the CNRSUBO facility

to the other three main processes; however, when looking at the overall impact, it contributes to around $60 \%$ in each of the impact categories, which is less than the $80-90 \%$ from literature and as evident from Langage-SU in Fig. 7b. One of the reasons for that different behaviour is the intensive use of flocculants, as mentioned above; the other reason is the highly frequent operation of the harvesting membrane, demanding high-energy consumption from filtration and cleaning processes.

Figure 8 presents a more in-depth look into the different processes at each facility. The major hotspot between CNRSUBO and Innolab-UG pilot facilities and in literature is the electricity demand [26, 28]. For Innolab-UG and CNRSUBO, the electricity is provided through the national grid; the data used are from the electricity share in 2019, as listed in Table 4. The nuclear power share is the dominant one; hence, the unfavourable environmental impact goes along with natural gas. It is, however, predicted to decrease significantly in the coming years if the energy transition continues and will reach considerably higher shares of renewable energy supply at the national scale. Dissimilarly, the 
a) $\quad$ Electricity $\square$ Reactor $\square$ Cleaning $\square$ Water Drying additives $\square$ Hydrolysation additive $\square$ Glucose $\square$ cO2

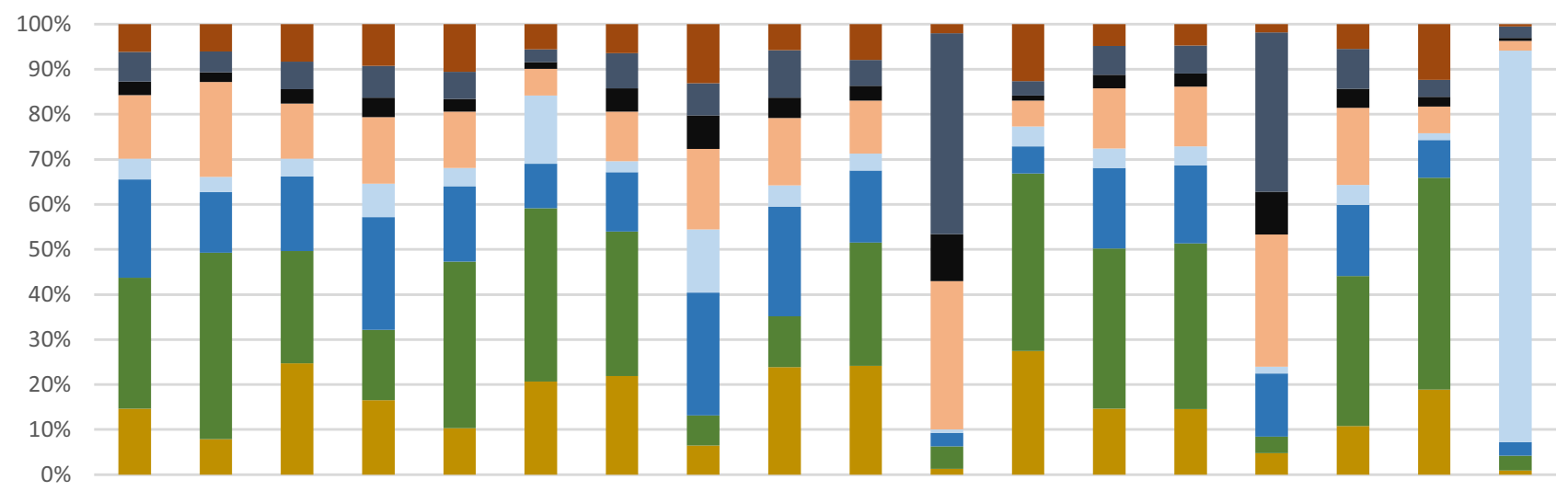

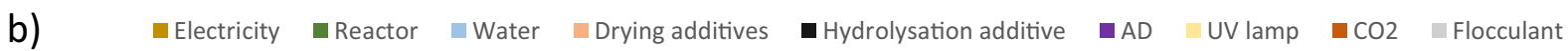
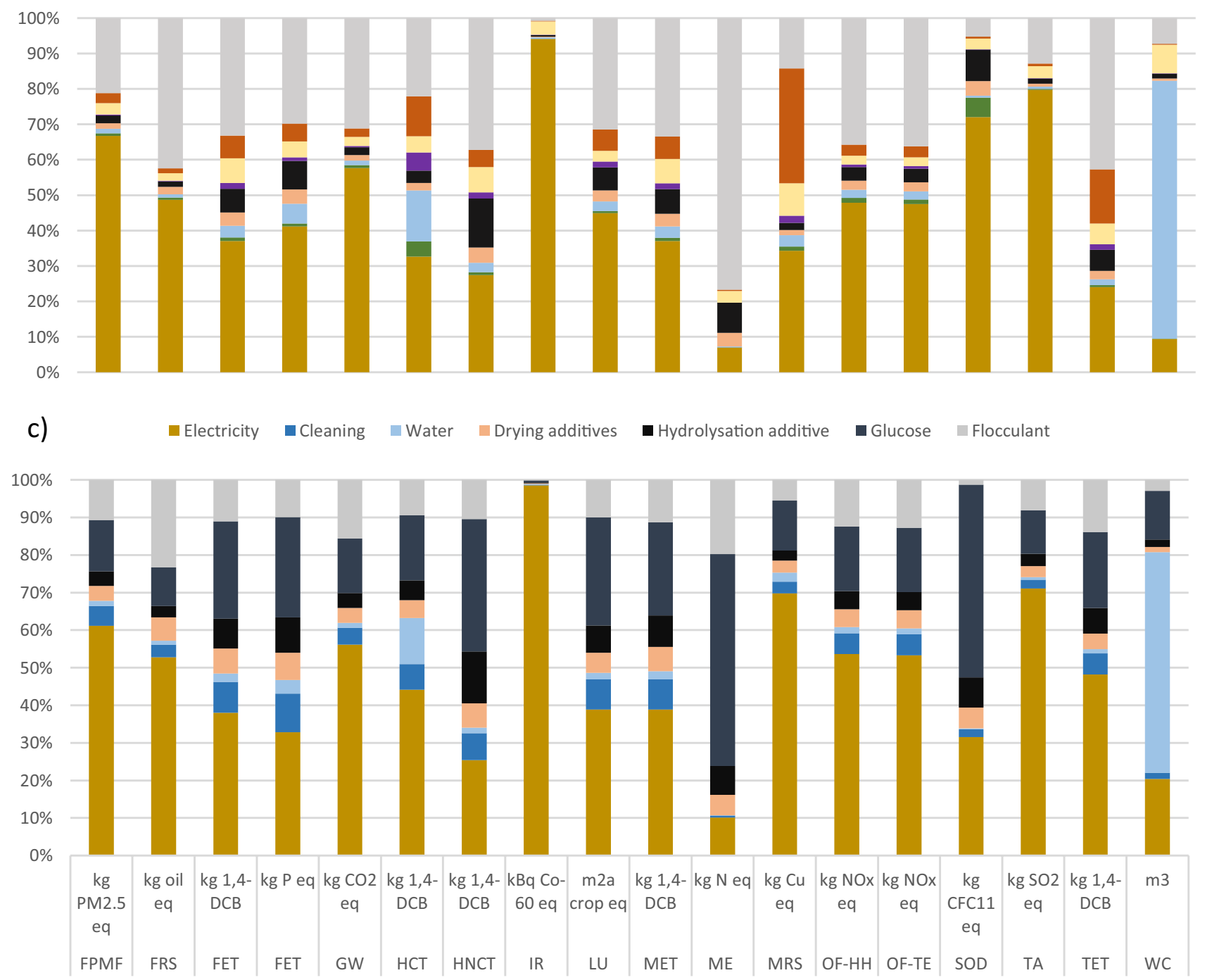

Fig. 8 Hotspot analysis of the three ALG-AD pilot plants showing system processes with the highest contribution to the overall impact. a Langage-SU, b Innolab-UG, and c CNRS-UB 
electricity consumption at the Langage-SU facility is relatively low due to the dependence of the pilot facility on the internally produced energy from the biogas plant. However, it should be mentioned that with a scale of 3,000 m3 for Langage AD with annual electricity production of around 4, $200 \mathrm{MWh}$, it is a lot smaller than those associated with the pilot plants in Innolab-UG and CNRS-UBO and yet only contributes an average of $20 \%$ to the environmental impact categories (Fig. 8a). The second hotspot of the Langage-SU facility is the PBR. The relatively large volumetric capacity coupled with a short lifetime and a low production capacity lead to the dominance of the bioreactors in the Langage-SU hotspot assessment.

The use of cleaning detergents is frequent at the LangageSU facility, especially in tap water treatment which is done on-site to prevent contamination while maintaining the water at a warm temperature. The impact of bleach, neutralizing agent, and sulphuric acid is rarely highlighted in the literature; it is usually ignored or manifested in water consumption. The need for intensive cleaning of the harvesting membrane at the CNRS-UBO facility and the high harvesting frequency also made the impact of cleaning for CNRS-UBO noteworthy. For CNRS-UBO and Innolab-UG facilities, the high ratio of flocculant use in the decanting centrifugation process for initial digestate treatment has significantly influenced the overall environmental impact of the two facilities. The drying additives are also considered hotspots in the case of the three facilities due to the high environmental impact of maize starch which acts as the raw material of those additives. Although used at a small ratio, enzymes produced from potato starch and bacterial strain and utilizing heat and electricity are also evident in the hotspot analysis, especially in the case of CNRS-UBO due to the relatively large biomasspaste quantities. Finally, since carbon dioxide is essential for phototrophic cultivation, pressurized carbon dioxide bottles were used regularly for $\mathrm{pH}$ regulation. The high processing and material demand in producing these bottles are reflected in the hotspot analysis of Innolab-UG and Langage-SU.

The difference in production capacity of Langage-SU to that of Innolab-UG, although cultivating the same species, is due to the application of a mixotrophic process at Langage-SU. Even though the harvested capacity of Langage-SU is only $300 \mathrm{~L}$, whereas the capacity at Innolab-UG is $400 \mathrm{~L}$, the final algal biomass production of Langage-SU is more than 10 times that of Innolab-UG. However, the mixotrophic phase is more prone to crashing due to contamination, so the need for a sterile medium is crucial [29]. On the other hand, the heterotrophic cultivation at CNRS-UBO has the edge over the other facilities due to the frequency and amount of harvest, twice per batch and 1, 500 L per batch, respectively. These factors have overcome the advantage of the mixotrophic phase at Langage-SU, having the highest biomass productivity. Heterotrophic seems advantageous as a cultivation type, especially in regions with shorter and weaker daylight, as it avoids the need to supply carbon dioxide and lighting. The benefits can be captured in regions like NWE, with low average temperatures and less sunlight during wintertime, as here mixotrophic algae cultivation is a balanced compromise between good insulation for lower heating load, thus impeding light penetration open-air or greenhouse while consuming more heat energy [30].

Without any technological improvement, the facilities within the ALG-AD could increase their production capacity within the same available space; PBRs can be larger in volume while occupying the same surface area due to the possibility of having multi-layer H-PBR and taller V-PBR. However, this upgrade would require more material and energy consumption, like more inputs to the culture, more reactor construction materials, and more operating hours of equipment. The yield of such a simple upgrade would lead to a drastic change in the environmental impact, although staying at a pilot scale. According to Smetana, Sergiy et al., studies showed that a $2.5 \mathrm{~m} 3$ heterotrophic reactor, $25 \mathrm{~m} 3$ PBR, and an open raceway pond of $300 \mathrm{~m} 3$ could yield (1.4-1.8 t/year) dry algal biomass [31], in comparison to the ALG-AD facilities where the $1.5 \mathrm{~m}^{3}$ heterotrophic reactor at the CNRS-UBO facility, yields around 1 ton/year of dried biomass, bearing in mind the change in growth rates between species. And at Langage-SU, a $0.3 \mathrm{~m} 3$ mixotrophic bioreactor being harvested weekly, which yields around 0.5 ton/year of dried biomass. From these values, it is feasible to conclude that it is feasible to maximize the production capacity of the facilities with at least a factor of 2 without requiring new resource-intensive equipment nor facility expansion.

\section{Comparison Between the Base and Reference Scenarios}

Soybean meal is modelled and assessed at $1 \mathrm{~kg}$, matching the functional unit of $1 \mathrm{~kg}$ algal dried biomass. Comparing the impact of the SM from Brazil in this study with the one from [23], it shows that from this model, the impact of SM is twice as much as the one from them. Having only used their transportation data implies that the differences are due to SM's plantation, processing, and local transportation. As seen from Table 4, the impact on acidification is around $8.7 \mathrm{~kg} \mathrm{SO} 2 \mathrm{eq}$, whereas in their study, the acidification impact in case of the $\mathrm{CW}$ scenario is $4.6 \mathrm{~kg} \mathrm{SO} 2$ eq for $1 \mathrm{t}$ of SM; also, climate change impact was $960 \mathrm{~kg}$ $\mathrm{CO} 2$ eq in their case while in this study, 1460. In da Silva, Vamilson Prudêncio et al., they fed their model with data from a Spanish report, and due to the language barrier, it was hard to pinpoint the key differences [23]. 
a)

- Langage-SU_EM $\square$ Langage-SU_IH $\square$ Langage-SU_IC

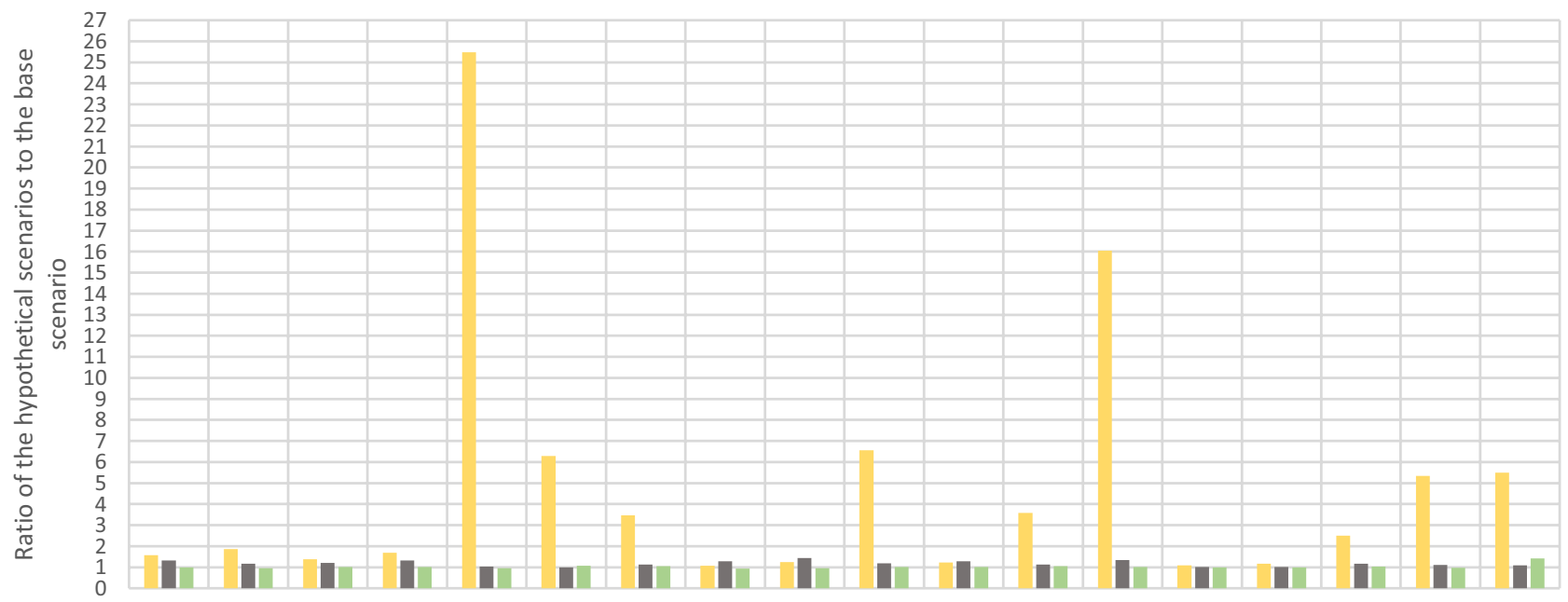

b)

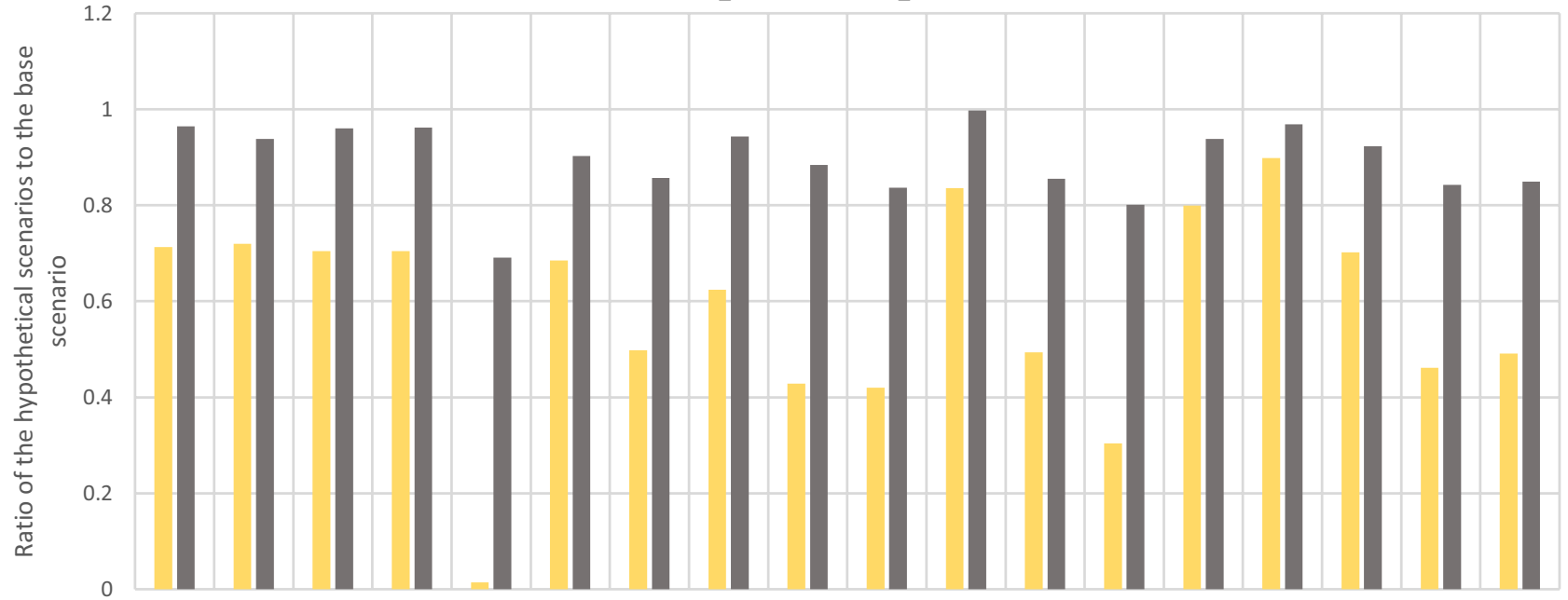

c)

Innolab-UG_IE Innolab-UG_IC

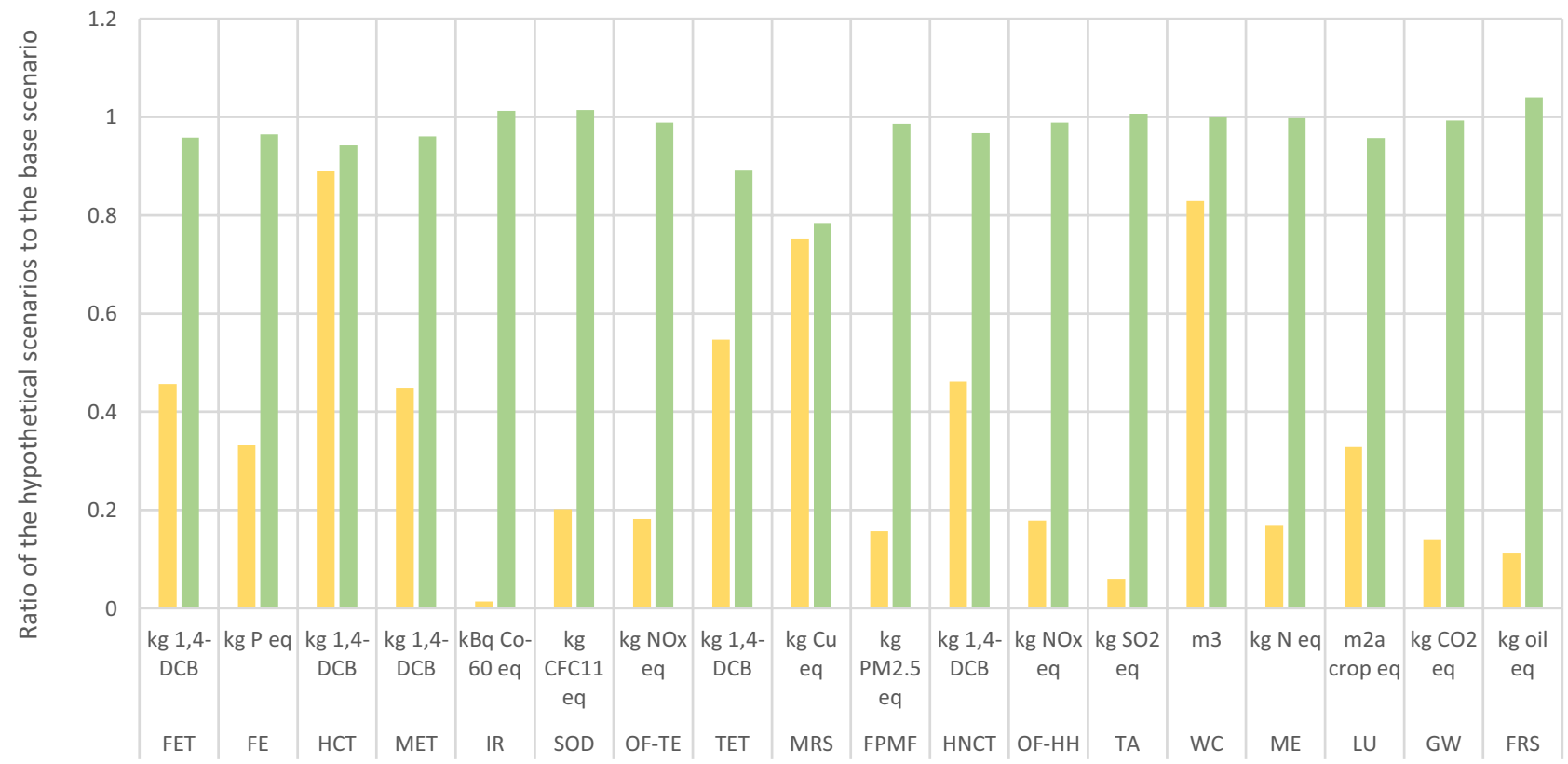


4Fig. 9 Sensitivity analysis of three hypothetical scenarios for the three ALG-AD pilot plants, with electricity from the grid (EM), heat from the biogas plant (IH), carbon dioxide recovery from the biogas plant (IC), and electricity from the biogas plant (IE). a Langage-SU, b CNRS-UBO, and c Innolab-UG

Microalgae as a feed source have been mentioned many times in literature to be a good substitute for SM and even have health benefits that SM lacks regarding protein content, carotenoid contents, and omega 3 fatty acids [32-34]. Moreover, the decentralization and local economic goals can be empowered through improving and encouraging local production. However, comparing an immature technology as microalgae cultivation to a mature one, SM, is made not to declare a winner but rather show the potential and hotspots for improvement so that the developing technology could replace or be an alternative for diversity. Taelman et al. pointed out that as a result of a sensitivity analysis, they found out that microalgae cultivation could impact the same scale as SM if the energy sources are dependent on renewable energies and by using more efficient equipment [10]. Our results support this conclusion.

\section{Sensitivity Analysis}

The sensitivity analysis aims to assess the significance of potential improvements to the system and to present scientific recommendations for the sustainable development of the technology. Three different hypothetical scenarios were conducted regarding the source of electricity, recovery of $\mathrm{CO} 2$, and heat. All data used to replace the relevant inputs for the sensitivity analysis can be found in the supplementary information in Table S3.

Source of electricity This scenario differs from the base scenario in that the energy source for the pilot plant LangageSU comes from the electricity grid of the UK. The electricity mix of the UK is shown in Table 4 along with the one of France and Belgium. On the other hand, in case of InnolabUG and CNRS-UBO, the electricity source is modelled to be coming from the biogas plant through a CHP unit.

CO2 recovery from a biogas plant This scenario differs from the base scenario in that the $\mathrm{CO} 2$ needed during the autotrophic phase comes from the AD plant instead of using industrial $\mathrm{CO} 2$ bottles. There are three main types of $\mathrm{CO} 2$ separation, either pre-combustion, post-combustion, or oxyfuel combustion [35]. A commonly applied CO2 separation method is used for the hypothetical scenario purpose, precombustion with the absorption process $[35,36]$. Data used for the model could largely deviate in real life as it is mainly based on assumptions and approximations due to the lack of data in the literature regarding $\mathrm{CO} 2$ recovery technologies.

Waste heat recovery In the case of Langage-SU and CNRS$\mathrm{UBO}$, heat from the CHP unit at the biogas plant is transported to the microalgae facility. This hypothetical scenario aims to show the impact of using the heat already produced at the biogas plant. Since this is not considered as waste heat, the CHP unit thermal parts were considered alongside the heat exchanger, vents, and ducts to transfer the heat. All data are acquired from ecoinvent database v3.5 and scaled-down/ up in line with approximations based on area and load [37].

\section{Sensitivity Analysis Results}

A sensitivity analysis was carried out using four hypothetical scenarios; the results are shown in Fig. 9. The plot depicts the deviation of the scenarios from the base scenario, a value of more than 1 , meaning more significant impact and vice versa.

Langage-SU In the case of Langage-SU, changing the energy source to the electricity grid instead of the biogas plant resulted in a significant increase in the environmental impact from 9 indicators, as shown in Fig. 9a. The IR increase of a factor of 26 is due to the nuclear share in the electricity mix of UK Table 4. In contrast, the increase from the SOD, FPMF, and TA indicators comes from the percentage of bioenergy in the grid. The boost in the GW, FRS, FF-HH, and OF-TE impacts results from the share of natural gas and hard coal in the UK grid, which contributes most to the land use indicator. The other two scenarios, heat from the CHP unit and $\mathrm{CO} 2$ recovery from flue gases, do not depict any significant increase or decrease in the environmental impact.

In the case of internal usage of heat, the increase in the impact from some indicators originates from the extra instalments necessary to transfer the heat. Finally, the recovery of $\mathrm{CO} 2$ from the biogas plant is almost only dominant from an impact point of view compared to the base scenario in the FRS indicator, which is due to the handling processes of pure CO2. The fluctuation of the Langage-SU_IC scenario compared to the base scenario is small and thus should be neglected due to the inaccuracy of the IC scenario model.

CNRS-UBO As a heterotrophic cultivation facility, glucose from a waste source like cellulose or factory waste (wastewater) would have projected less environmental impact than the highly concentrated corn syrup used at CNRS-UBO [38]. However, there is no experimental data that suggests the same productivity and if at all, growth of Aurantiochytrium $m$., so only two scenarios were chosen for the sensitivity analysis of this facility. As shown in Fig. 9b, the use of 
internal heat generated in the AD plant has led to a decrease in the environmental impact in all impact categories. This is due to lowering the electricity consumption from the grid and relying instead on a heat pump from the CHP unit. The lower impact of internal energy utilization is even more redundant for the other scenario CNRS-UBO_IE, where all electricity used at the pilot facility comes from the biogas plant. The maximal impact reduction in IR indicator is a result of nuclear power evasion, which shares $70 \%$ of the electricity grid mix (see Table 4). A significant reduction in MRS is also due to avoiding nuclear-based energy production. Other footprints reduction results from avoiding power generation from conventional power plants like in GW and FRS. The major hotspots of the French electricity grid are nuclear, traditional power plants, and gas engine energy sources.

Innolab-UG For the scenario Innolab-UG_IE in Fig. 9c, where the facility depends on energy generated at the $\mathrm{AD}$ plant, the environmental footprint has also significantly improved similarly to the CNRS-UBO case. The differences in the magnitudes of improvement like in GW and other indicators are due to the more significant share of natural gas and bioenergy and the smaller share of nuclear in the Belgian electricity grid compared to the French one. For the other scenario where $\mathrm{CO} 2$ is recovered from flue gases instead of being supplied in bottles, the potential of improvement exists but not at small scale.

\section{Significance of the Results and Their Limits}

With primary experimental data from three microalgae pilot facilities with individual settings at different locations to feed the life cycle assessment (LCA) model, this study aims to bridge the data and knowledge gap identified in the literature. With the LCA, we help to close the knowledge gap on the environmental chances and challenges of combining microalgae cultivation with biogas production to create added value and establish a reliable and resilient circular bio-economy at local scale. In theory, coupling of microalgae and biogas technology looks like a win-winconstellation by reducing biogas plants' negative environmental impacts by supplying nutrients and electricity, heat, and $\mathrm{CO} 2$ to microalgae cultivation. The three investigated facilities Langage-SU, CNRS-UBO, and Innolab-UG were all performing as bio-refineries in correspondence to existing $\mathrm{AD}$ plants.

The comparison of the environmental impacts of the young microalgae technology with the well-established soybean meal production is limited since the technologies are at different stages of maturity. The LCA results of the three facilities indicate that further development and experiments are needed to improve the existing technologies and processes and investigate how coupling of biogas and microalgae technology can be reached in a more environmentally friendly way. One reason for the less favourite results of the algal-based feed production is that technologies and processes are still under development and not yet commercial.

In addition, conducting an LCA for microalgae technologies is challenging to develop a consistent and comparable data inventory with real data from pilot plants. This requires a structured and consistent approach, e.g. a detailed questionnaire, a profound biological and technical understanding of both technologies, an iterative and multi-layered literature search, and close cooperation with the technicians of the pilot plants.

Performing sensitivity analysis helps to understand potential improvements while changing specific criteria for the technological performance and the process settings. The hypothetical scenarios used for the sensitive analysis were based on sustainable means of improving the technology, particularly the internal usage of electricity and/or heat and $\mathrm{CO} 2$ recovery. The results indicate that the environmental benefits of electricity use from biogas plants are much more significant than internal heat or $\mathrm{CO} 2$ use. It has to be noted that the uptake of nutrients from the digestate has environmental advantages, but large algae cultivation units operating at a continuous mode are needed to uptake significant amounts of the liquid and pretreated digestate from biogas plants as the nutritional source for growing microalgae. The second main advantage is using the harvested and post-treated algal biomass as a source for animal feed, thus replacing imported soybean meal and closing in the regional nutrients cycle.

There is a broad scope of scenarios to investigate potential technological improvement from the environmental footprint perspective. However, the sensitivity analysis for this study was limited to only a few studies for each facility due to time and data availability limitations. Hypothetical scenarios to investigate the maximum production capacity according to space limitation would conclude an evidential assessment of the sustainability of this technology and thus its applicability at an industrial scale. Another scenario could be the recycling of wastewater to reduce water demand and the water footprint of algae cultivation which would have to be well treated for other than cleaning purposes to prevent the culture from contamination. Electricity supply from other renewable energy sources would also be a very promising analysis compared to electricity from the biogas plant. Depending on the region and the feedstock of the biogas plant, more efficient digestate treatment methods should be applied, which are less energy and material intensive, like paper filtration. Given these many and different proposals for improving combining the microalgae and the biogas technology identified, further research in this area is considered highly promising. 


\section{Conclusions}

Nitrogen is an essential nutrient to support life but is poorly managed and mainly neglected in many transition pathways to sustainable agriculture. On the one hand, in regions with a high density of livestock farms and biogas plants, sustainable nitrogen management is a challenge that needs to be addressed with novel strategies to reduce the negative impacts on the environment, ecosystems, and human health. On the other hand, microalgae cultivation as a source of renewable biomass with many potential applications faces the challenge of finding a possible nutrient source acceptable for supplying at a large scale. Combining the innovative microalgae technology with the established biogas technology is an uncomplicated technological approach to sufficiently reduce the nutrient load of the biogas digestate. It offers two main advantages. First, pretreated biogas digestate provide suitable nutrients for microalgae cultivation. Thus, in regions with intensive livestock farming based on feedstock imports and biogas production, groundwater is prevented from a further increase in nitrate content, as the microalgae extract parts of the nitrogen contained in the biogas digestate. Second, the produced algal and post-treated algal biomass can be used as a source for animal feed, thus replacing imported soybean meal and closing the regional nutrients cycles. However, the LCA results show that imported soybean meal has significantly lower environmental impacts on human health and ecosystems than algal feedstock production. More research is needed to investigate further the impact of changing feeding strategies of the biogas fermenters and microalgae cultivation approach on the uptake of nutrients, the quality and quantity of algal feedstock produced, and the environmental impacts.

Supplementary Information The online version contains supplementary material available at https://doi.org/10.1007/s12155-022-10397-2 .

Acknowledgements The authors would like to acknowledge Louise Hall as ALG-AD project manager; Carole Llewellyn for her conception and design of the whole project and the overall project leadership; Khondokar Rahman and Roshni Paul for their support during data acquisition and the BCU team leader; Lynsey Melville, for her leadership and support; Alla Silkina and Claudio Fuentes Grunewald from Swansea University for their support during data acquisition; Vanessa, José Gayopalaez, and Gary for their support on data acquisition for the pilot plant Langage AD; Denis De La Broise, Phillipe Soudant, and Luc Chauchat for their support on data acquisition for the pilot plant CNRS-UBO; Barbara Clement Larosiere for her support on data acquisition for the pilot plant Cooperl AD; and Ivamyr, Marcella Fernandes De Souza, and Jai Sankar Seelam for their support on data acquisition for the pilot plant Innolab-UG. The authors would also like to acknowledge the all partners for their indirect contribution to this work and their efforts to advance this LCA work, partners responsible for creating the decision support tool, characterization, investment operation, and maintenance and partners accountable for the long-term work package.
Author Contribution Mohamed Elshamy has contributed by structuring the manuscript, data acquisition, performing the manuscript analysis, and writing the manuscript.

Christine Rösch, the corresponding author, participated in the design and coordination of the study and the data analysis. She drafted the original manuscript, made valuable inputs in preparing and writing the manuscript, and approved the final manuscript.

Funding Open Access funding enabled and organized by Projekt DEAL. This work was supported by the Interreg NWE funded project ALG-AD.

Data Availability All data generated or analysed during this study are included in this published article [and its supplementary information files].

\section{Declarations}

Conflict of Interest The authors declare no competing interests.

Open Access This article is licensed under a Creative Commons Attribution 4.0 International License, which permits use, sharing, adaptation, distribution and reproduction in any medium or format, as long as you give appropriate credit to the original author(s) and the source, provide a link to the Creative Commons licence, and indicate if changes were made. The images or other third party material in this article are included in the article's Creative Commons licence, unless indicated otherwise in a credit line to the material. If material is not included in the article's Creative Commons licence and your intended use is not permitted by statutory regulation or exceeds the permitted use, you will need to obtain permission directly from the copyright holder. To view a copy of this licence, visit http://creativecommons.org/licenses/by/4.0/.

\section{References}

1. Ketzer F, Skarka J, Rösch C (2018) Critical review of microalgae LCA studies for bioenergy production. BioEnergy Res 11(1):95-105

2. Chew KW et al (2017) Microalgae biorefinery: high value products perspectives. Bioresour Technol 229:53-62

3. Shahid A et al (2020) Cultivating microalgae in wastewater for biomass production, pollutant removal, and atmospheric carbon mitigation; a review. Sci Total Environ 704:135303

4. Astals $S$ et al (2015) Anaerobic co-digestion of pig manure and algae: impact of intracellular algal products recovery on co-digestion performance. Biores Technol 181:97-104

5. Fuentes-Grünewald $\mathrm{C}$ et al (2021) Towards a circular economy: a novel microalgal two-step growth approach to treat excess nutrients from digestate and to produce biomass for animal feed. Bioresour Technol 320:124349

6. Dalgaard R et al (2008) LCA of soybean meal. Int J Life Cycle Assess 13(3):240-254

7. Boerema Annelies et al (2016) Soybean trade: balancing environmental and socio-economic impacts of an intercontinental market. PloS one 11(5):e0155222

8. FAO (2006) Plant nutrition for food security - a guide for integrated nutrient management FAO Fertilizer and plant nutrition bulletin, 16 ISBN 92-5-105490-8. Available at http://www.fao. org/fileadmin/templates/soilbiodiversity/Downloadable_files/ fpnb16.pdf 
9. FAOSTAT FAO (2020) online statistical database. Available at http://www.fao.org/faostat/en/ Accessed December 2020

10 Taelman SE et al (2015) Environmental sustainability analysis of a protein-rich livestock feed ingredient in the Netherlands: microalgae production versus soybean import. Resour Conserv Recycl 101:61-72

11. GIZ (Deutsche Gesellschaft für Internationale Zusammenarbeit) (2019) Towards more sustainability in the soy supply chain: how can EU actors support zero deforestation and SD efforts? Available at https://irp-cdn.multiscreensite.com/be6d1d56/files/uploa ded/Sustainability\%20in\%20Soy\%20supply\%20chain_consolidat ed\%20study\%20\%282\%29_final.pdf

12 J. Poore T (2018) Nemecek Reducing food's environmental impacts through producers and costumers. Science 360(6392):987-992. https://doi.org/10.1126/science.aaq0216

13. Singh J, Sai Gu (2010) Commercialization potential of microalgae for biofuels production. Renew Sustain Energy Rev 14(9):2596-2610

14. International Organization for Standardization (2006) Environmental Management: Life Cycle Assessment; Principles and Framework. ISO.

15 Finkbeiner $M$ et al (2006) The new international standards for life cycle assessment: ISO 14040 and ISO 14044. Int J Life Cycle Assess 11(2):80-85

16. Onorato C, Rösch C (2020) Comparative life cycle assessment of astaxanthin production with Haematococcus pluvialis in different photobioreactor technologies. Algal Research 50:102005

17 Wernet $G$ et al (2016) The ecoinvent database version 3 (part I): overview and methodology. Int J Life Cycle Assess 21(9):1218-1230

18. Schleiss K, Jungbluth N (2007) anaerobic digestion plant construction, agriculture, with methane recovery I anaerobic digestion plant, agriculture, with methane recovery. $\mathrm{CH}$ Alloc Ecoinvent Database Version 3:5

19. Jungbluth $\mathrm{N}$ et al. (2007) Life cycle inventories of bioenergy. Final report ecoinvent data v2.017

20. Ruggiero MA et al (2015) A higher level classification of all living organisms. PloS one 10(4):e0119248

21. Leyland B, Leu S, Boussiba S (2017) Are thraustochytrids algae? Fungal Biol 121:835-840

22. Marchan LF, Chang KJL, Nichols PD, Mitchell WJ, Polglase JL, Gutierrez T (2018) Taxonomy, ecology and biotechnological applications of thraustochytrids: a review. Biotechnol Adv 36:26-46

23 da Silva VP et al (2010) Variability in environmental impacts of Brazilian soybean according to crop production and transport scenarios. J Environ Manag 91(9):1831-1839

24. Scherer MD et al (2017) Environmental study of producing microalgal biomass and bioremediation of cattle manure effluents by microalgae cultivation. Clean Technol Environ Polic 19(6):1745-1759
25 Huijbregts MAJ et al (2017) ReCiPe2016: a harmonized life cycle impact assessment method at midpoint and endpoint level. Int J Life Cycle Assess 22(2):138-147

26 Taelman SE et al (2013) The environmental sustainability of microalgae as feed for aquaculture: a life cycle perspective. Bioresour Technol 150:513-522

27. Pérez-López P et al (2014) Life cycle assessment of the production of the red antioxidant carotenoid astaxanthin by microalgae: from lab to pilot scale. J Clean Prod 64:332-344

28. Pérez-López P et al (2017) Comparative life cycle assessment of real pilot reactors for microalgae cultivation in different seasons. Appl Energy 205:1151-1164

29. Zhan J, Rong J, Wang Q (2017) Mixotrophic cultivation, a preferable microalgae cultivation mode for biomass/bioenergy production, and bioremediation, advances and prospect. Int J Hydrogen Energy 42(12):8505-8517

30 Baliga R, Powers SE (2010) Sustainable algae biodiesel production in cold climates. Int J Chem Eng 2010:1-13

31 Smetana $\mathrm{S}$ et al (2017) Autotrophic and heterotrophic microalgae and cyanobacteria cultivation for food and feed: life cycle assessment. Bioresour Technol 245:162-170

32 Lum KK, Kim J, Lei XG (2013) Dual potential of microalgae as a sustainable biofuel feedstock and animal feed. J Anim Sci Biotechnol 4(1):1-7

33 Becker EW (2007) Micro-algae as a source of protein. Biotechnol Adv 25(2):207-210

34 Dineshbabu G et al (2019) Microalgae-nutritious, sustainable aqua-and animal feed source. J Funct Foods 62:103545

35. Volkart K, Bauer C, Boulet C (2013) Life cycle assessment of carbon capture and storage in power generation and industry in Europe. Int J Greenhouse Gas Control 16:91-106

36. Blomen E, Hendriks C, Neele F (2009) Capture technologies: improvements and promising developments. Energy Procedia 1(1):1505-1512

37. Primas A, Hässig W (2007) ventilation system production, decentralized, $6 \times 120 \mathrm{~m} 3 / \mathrm{h}$, steel ducts, with earth tube heat exchanger I ventilation system, decentralized, $6 \times 120 \mathrm{~m} 3 / \mathrm{h}$, steel ducts, with earth tube heat exchanger I Cutoff U. Alloc Ecoinv Datab Vers 3:5

38. "Data \& Statistics - IEA". IEA, 2021, https://www.iea.org/dataand-statistics?country $=\mathrm{UK} \&$ fuel $=$ Energy $\% 20$ supply\&indicator $=$ ElecGenByFuel.

39. Rockström J et al (2009) Planetary boundaries: exploring the safe operating space for humanity. Ecol Soc 142:32

40 Steffen W et al (2015) Planetary boundaries: guiding human development on a changing planet. Science 347:6223

41. Mohan SV et al (2015) Heterotrophic microalgae cultivation to synergize biodiesel production with waste remediation: progress and perspectives. Bioresour Technol 184:169-178

Publisher's Note Springer Nature remains neutral with regard to jurisdictional claims in published maps and institutional affiliations. 